\title{
Investigating Levels of Low Frequency Magnetic Field in the Inhabited Vicinity of Power Transmission Lines of Kuwait
}

\author{
Fuad M. Alkoot \\ Higher Institute of Telecommunication \& Navigation, PAAET, Shuwaikh, Kuwait \\ Email: $\underline{\mathrm{f} \text { alkoot@yahoo.com, fm.alkoot@paaet.edu.kw }}$
}

Received 2 May 2015; accepted 26 June 2015; published 30 June 2015

Copyright (C) 2015 by authors and Scientific Research Publishing Inc.

This work is licensed under the Creative Commons Attribution International License (CC BY). http://creativecommons.org/licenses/by/4.0/

(c) (i) Open Access

\begin{abstract}
According to surveyed literature, there may be a health hazard associated with extremely low frequency magnetic fields. This study aims at presenting a recent survey of this literature. It also aims at measuring magnetic field levels close to power transmission lines at inhabited areas in Kuwait to see if current levels are safe and to establish a database of $50 \mathrm{~Hz}$ magnetic field levels at inhabited areas. Measurements were made, according to the international standard procedures in winter, spring, summer and fall, and three times of a day. Four inhabited areas were surveyed. Results provide us with an independent view of the levels in the vicinity of power lines and houses. Results show that the highest level is measured in the summer, reaching $115 \mathrm{mG}$ while the minimum level is measured in the fall. We found that some houses were at less than $\mathbf{5 0}$ meters distance from the edge of the transmission lines. Some houses were, as close as 22 meters to the line. We found that levels at the entrance of houses and at outdoor parking areas were mostly higher than $4 \mathrm{mG}$.
\end{abstract}

\section{Keywords}

LF-EMF, Power Transmission, EMF Survey, EMF Monitor, EMF Measurement, Magnetic Field

\section{Introduction}

High frequency electromagnetic radiation and low frequency magnetic fields are associated with health disorders by a growing number of scientists. Therefore, many countries and organizations have conducted epidemiological studies to find a relation between radiation and diseases. The investigations are progressing towards further proof of the health hazards associated with high frequency radiation and low frequency fields. In 2011, the 
WHO has classified it as a possible carcinogen. Limits have been set by many organizations and countries, due to the possibility of existing health hazards. However, these basic restrictions are not to be considered as values that determine the threshold for definite occurrence of adverse health effects. They merely indicate an increase in the probability of adverse effects occurring above the restrictions. These restrictions are intended to avoid adverse health consequences by limiting current density from $50 \mathrm{~Hz}$ fields in the Central Nervous System (CNS). Consequently, many countries have monitored sources associated with these fields and determined locations of possible hazard. The studies of Shangzun et al. [1], Tukimin et al. [2], Karipidis and Martin [3], Mamishev and Russell [4], DiPlacido et al. [5], Habiballah et al. [6], Said et al. [7] are some studies that conducted measurement surveys at inhabited areas and aimed to find if levels were within limits.

Here we aim to measure, at the inhabited areas of Kuwait, the magnetic field levels due to transmission lines. A sample of transmission lines close to locations accessible by the public were selected for measurement. Spot measurements were conducted at each location under investigation at a height of one meter. The visit to a location was repeated at three times of a day, morning, afternoon and night, to record levels at different load conditions. This has been repeated at four seasons: winter, spring, summer and fall. Each transmission line location was measured at various spots starting from center of parallel lines under the cable and at five lateral locations at ten meter distances perpendicular to the line, spanning at least 50 meters. This is repeated at 100 meter longitudinal distances from the previous location under the line. Levels at all of these locations adhere to the international limits, however, the field level at many locations exceeds the limit of $4 \mathrm{mG}$ set by Ahlbom et al. [8]. There is a need for this full scale study that yields a table of levels at various locations, because none has been conducted in Kuwait. Previous studies by Alkoot and Zaeri [9] [10] were pilot studies that did not include the different lateral distances and details included in the current study. The study by Qabazard [11] was at only one longitudinal spot of one residential area. Additionally, we need to confirm that the area around the lines is safe especially at the perimeters of the houses and at the parking spaces or gardens established outside of these houses. High levels found at the perimeters of houses indicate a need for a measurement inside these houses. Our study also aims to confirm that houses are at 50 meters, and that levels reduce to below $4 \mathrm{mG}$ at 50 meters from transmission lines. The contributions of this paper can be summarized as follows:

1) A survey of research paper and epidemiological studies involving the health hazards related to electromagnetic fields.

2) A field survey of field levels around high power transmission lines at inhabited areas, to confirm levels do not exceed standard limits.

3) Verify if houses are at a safe distance from power transmission lines.

4) Provide the scientific community and the public in Kuwait with the first trusted table of field levels that were collected using international standards and professional equipment.

In the next section we survey the epidemiological studies that investigate the possibility of health hazards associated with electromagnetic field and electromagnetic radiation. This survey shows the necessity of monitoring field levels and confirming that houses are at a safe distance from field sources. In Section 3 we discuss the technical requirements of the magnetic field survey and the measurement methodology, followed by results in Section 4. A discussion of results is presented in Section 5. The paper is brought to conclusion in Section 6.

\section{ELF-EMF Associated Health Hazard}

Research on the health effects of electromagnetic field began in the late 1960's and was originally focused on electric fields. Wertheimer et al. [12] reported a statistical association between magnetic field exposure and distance between a power line and someone's home, and two- to three-fold increases in leukemia risk among U.S. children. This early research brought the issue of magnetic field-related health risks to the attention of scientists and the public. Two studies by Green et al. [13] and Schuz et al. [14] have reported an association between Extremely Low Frequency - Electric and Magnetic Field (ELF-EMF) and Leukemia. The strongest evidence that ELF-EMF exposures pose health effects comes from associations observed in human populations with two forms of cancer: childhood leukemia and chronic lymphocytic leukemia in occupationally exposed adults. Ahlbom et al. [15] discusses the different studies which claim the association between the low frequency fields and brain cancer, lymphomas and breast cancer diseases. They found the strongest link between exposure and childhood leukemia, where a statistically significant association between childhood leukemia and average exposure for 24 - 48 hours of $0.4 \mathrm{~T}$ or greater was found, $(0.4 \mathrm{~T}=4 \mathrm{mG})$. This was confirmed by Kheifets et al. 
[16] when the study from Brazil was excluded. A study in the US by Foliart et al., [17] investigated the relationship between ELF-EMF and survival after childhood acute lymphoblastic leukemia. It showed poorer survival related to ELF-EMF exposures higher than $0.3 \mathrm{mT}$. Other diseases that were lately investigated include neurodegenerative disorders, suicide and depression due to its effect on the melatonin levels, cardio vascular disorders and immune system. Other rich sources that discuss investigations on health risk associated to ELF-EMF are the WHO [18] report, the Bioinitiative report by David Carpenter and Cindy Sage [19], the ICNIRP SCI report by Ahlbom et al. [8] and the California EMF report [20]. Some conclude that the evidence does not support the claim of diseases caused by ELF-EMF except for cancer. WHO [18] concludes that recent studies show evidence of DNA damage at field levels of $350 \mathrm{mG}$. Additionally, evidence supports that ELF-EMF yields potential changes to mental processes such as attention and memory, as well as to regulatory functions within the body.

Furthermore, many studies link between exposure to power frequency fields and breast cancer, lymphoma, liver cancer, skin cancer and brain cancer in animals. The highest relative risk that was shown by Feychting and Ahlbom [21] drew most attention, while Loomis [22] showed a clear association of female breast cancer with occupational exposure to power low frequency fields. Strongest evidence for a connection between power frequency fields and many diseases in addition to cancer was found by Neutra et al. [23]. A meta-analysis of studies on ELF-MF and childhood brain tumor risk did not find the same effect seen in the leukemia studies, (Kheifets et al., [24]).

Magda Havas [25] discusses the effect of EMF, and concludes that EMF does affect living systems, where the critical distance appears to be at 50 meters from a power line, and the critical magnetic flux densities are above $0.2 \mathrm{~T}$ (2 mG). The paper discusses many studies that have shown an association between three types of cancer, in addition to other disorders, and ELF-EMF.

Joachim Schuz [26] also presents and discusses the outcome of many studies on hazardous effects of ELF-EMF and concludes that the assessment that ELF-EMF are a possible carcinogen and may cause childhood leukemia remains valid. The pooled analysis works of many are discussed and a graphical comparison of the works by Kheifets et al. [16] and Ahlbom et al. [8] were discussed. Based on these studies a conclusion is reached that recent pooled analysis confirm results from previous studies that approximately a twofold risk increase at ELF-EMF exposures above or equal to $4 \mathrm{mG}$ exists. However, little evidence exists for an association between childhood brain tumor and ELF-EMF. It concludes that the current best estimate is that about $1 \%$ of all childhood leukemia cases in Europe or 3\% in North America would be attributable to exposure to ELF-MF.

In addition to different types of cancer, ELF-EMF was found to be a possible cause of miscarriage among women living close to power lines. This finding was also reported in Lee et al. [27]. International Association for Research on Cancer, (IARC) [28], has assigned EMF radiation to group 2B, which means it is a possible carcinogenic. The U.S. National Institute of Environmental Health Sciences (NIEHS) [29] has also classified it as a possible carcinogenic. Among other non-cancerous diseases caused by low frequency magnetic field levels electro sensitivity has been widely reported in Europe. However, different countries have reported it to be due to different electric equipment. Sweden and Finland reported electro sensitivity due to video display terminals, while Germany found it to be due to power frequency sources like T.V. and radio towers. They have also reported different kinds of sensitivity. In Sweden skin rash while in Denmark many other allergies were reported. Studies have also found that some can sense $6 \mathrm{~T}$ (i.e. $60 \mathrm{mG}$ ) power frequency fields, which is called EHS electromagnetic hypersensitivity.

The epidemiological studies and health reports by California Department of Health, California EMF Program, [20], the Bioinitiative report by David Carpenter and Cindy Sage [19], Dockerty et al. [30], Feychting and Ahlbom [21], Lee et al. [27], Green et al. [13], Loomis et al. [22], Linet et al. [31], McBride et al. [32], Neutra et al. [23], Savitz et al. [33], Schuz et al. [26], US National Institute of Environmental Health Sciences [34], and Wertheimer and Leeper [12], demonstrate a fairly consistent pattern of small increased risk with increasing exposure. However, no indication of increased leukemia in experimental animals has been observed. The lack of connection between the human data and the experimental data (animal and mechanistic) complicates the interpretation of these results. Accordingly the British National Radiological Protection Board (NRPB) Advisory Group on Non-Ionizing Radiation [35] have concluded that ELF-EMF exposure cannot be recognized at this time as entirely safe because of scientific evidence that exposure may pose a leukemia hazard. In general epidemiological studies have shown that adults show different reactions to the fields, with sick people being most sensitive, especially those with epilepsy or seizure. 
A case control study by Lowenthal et al. [36] shows an increased risk associated with residence at less than 300 meters from high voltage power lines. They find that those who had lived within $50 \mathrm{~m}$ had an odds ratio of 2.06 for developing lymphoproliferative disorders (LPD) or myeloproliferative disorders (MPD). Those who had lived between 50 and $300 \mathrm{~m}$ had an odds ratio of 1.30 . Those who lived within $300 \mathrm{~m}$ during the first 15 years of life had a threshold increase in risk odds ratio 3.23. Those who had lived the same distance aged 0 - 5 had a fivefold increase in risk with odds ratio 4.74 . The study raise the possibility that prolonged residence close to power lines, especially early in life may increase the risk of developing MPD and LPD at an older age.

\section{Technical Background and Methodology}

\subsection{Background}

A single-circuit AC transmission line has three conductors (or conductor bundles) with multiple voltage phases. The electrical environment in the vicinity of the lines is characterized by the electric field strength, $\boldsymbol{E}$, and the magnetic flux density, $\boldsymbol{B}$. In general, the electric field strength $\boldsymbol{E}$ at apoint in space can be represented as a rotating vector which traces an ellipse in a plane perpendicular to the conductors. Near ground level, the field ellipse degenerates to a nearly vertical line. In the absence of nearby objects or irregular terrain, the field strength changes slowly from ground level to a height of about 1 or 2 meters, i.e., the field is approximately uniform. At ground level the field vector oscillates along a line perpendicular to the ground. The magnetic field at a point near a three-phase transmission line can also be represented by a rotating vector in space but in contrast to the electric field, the vector $\boldsymbol{B}$ is a rotating vector even at ground level. $\boldsymbol{B}$ is given in units of Webers per square meter $(\mathrm{Wb} / \mathrm{m} 2)$ or Teslas $(\mathrm{T})$. This quantity is also measured in units of Gauss $(\mathrm{G})$, where 1 Tesla $=10,000$ Gauss. The principle of operation of a coil-type $\boldsymbol{B}$-field probe takes advantage of Faraday's law (in differential form)

$$
\nabla \times \boldsymbol{E}=-\frac{\partial \boldsymbol{B}}{\partial t}
$$

Using Stokes' theorem, this can be written in the form

$$
\oint \boldsymbol{E} \cdot \dot{\mathrm{d} l}=-\frac{\partial}{\partial t} \int_{A} \boldsymbol{B} \cdot \mathrm{d} \boldsymbol{A}
$$

where the integral on the left is a line integral along a curve enclosing a surface area $A$. If the path of the left-hand integral is taken to be a closed loop of conductor with area $A$, and $\boldsymbol{B}$ is a quasi-static uniform field normal to area $\mathrm{A}$, the line integral can be regarded as the voltage, $V$, developed across the ends of the loop in response to the time-rate-of-change in the magnetic flux $B A$. That is,

$$
V=\oint \boldsymbol{E} \cdot \dot{\mathrm{d}} l=-\frac{\partial}{\partial t}(B A)
$$

If the magnetic field is free of harmonics, e.g., $B=B_{0} \sin \omega t$, then

$$
V=-\omega B_{0} A \cos \omega t
$$

where $\omega$ is the angular frequency. It should be noted that the relationship between $V$ and $B_{0}$ given in the above equation assumes that the direction of $B_{0}$ is perpendicular to the plane of the coil, and this is the orientation for measuring the maximum B-field value, Misakian [37].

\subsection{Standard Requirements}

Many standards that set the procedures for measuring electric and magnetic fields exist. They are similar in meter requirements and measurement methodology. Some of the organizations that have set such standard procedures are the ICNIRP [38], IEEE [39] which was reaffirmed in 2002, the CDC report by Bowman et al. [40] and the ARPANSA procedure set by Karipidis [41]. Before presenting the meter used in our survey and measurement methodology we present the minimum standard requirements for the magnetic field meter and probe by quoting the IEEE [39] standard which was reaffirmed in 2002: "Magnetic field meters consist of two parts, the 
probe or field sensing element, and the detector, which processes the signal from the probe and indicates the rms value of the magnetic field with an analogue or digital display. Magnetic field probes, consisting of an electrically shielded coil of wire (i.e., a single-axis probe), must be used in combination with a voltmeter as the detector for survey type measurements of power frequency magnetic fields from power lines. Also available is instrumentation with three orthogonally oriented coil probes (three-axis meters) that simultaneously measures the rms values of the three spatial components and combines them to give the resultant magnetic field. Magnetic field meters measure the component of the oscillating (linearly polarized) or rotating (elliptically or circularly polarized) magnetic field vector that is perpendicular to the area of the probe(s).

In regard to the parameters affecting the measurements the IEEE [39] standard states that: "many of the difficulties described for making E-field measurements are not serious considerations for B-field measurements. Positioning the probe, reading errors, proximity effects of the observer or nearby (no conducting) objects, electrical leakage of probe handles, and no uniformity of the field have much less or negligible impact. Electrical shielding of the probe, however, is essential in avoiding induced currents from the ambient electric field."

The meter and probe used:

The meter used here is manufactured by NARDA with model number NBM-550 which provides the broadest frequency coverage of electric and magnetic fields. An NBM-TS Software is supplied with the NBM-550 meter that provides for convenient data management, and data evaluation.

The probe used is the EHP-50C model which performs $E$ and $\beta$ field measurements in the $5 \mathrm{~Hz}$ to $100 \mathrm{kHz}$ range with a dynamic range greater than $140 \mathrm{~dB}$ and built-in spectrum analyzer function. The EHP-50C, is used as a probe with the NBM550. Figure 1 is an image of both NBM550 and probe EHP50C. Figure 2 presents the display reading of the NBM550 showing the two possible measurement units. Using the software data can be downloaded to the computer for backup and further processing. Using the software the sample spectrum of field levels at different frequencies can be presented as in Figure 3.

Narrowband spectrum analysis capability of the EHP-50C makes it possible to measure only the contribution from the selected source - e.g. a high voltage line - excluding other nearby additional frequencies.

The EHP-50C's small cubic housing (approx. 4 in.) accommodates everything: three magnetic loops and three plate capacitors orthogonally positioned for sensing fields from any direction. Encased inside the housing is also

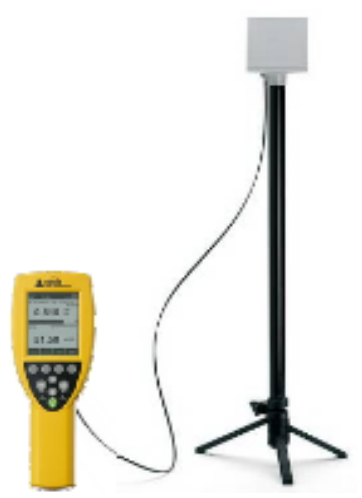

Figure 1. the EHP50C probe connected to the NBM550 meter through a fiber cable.
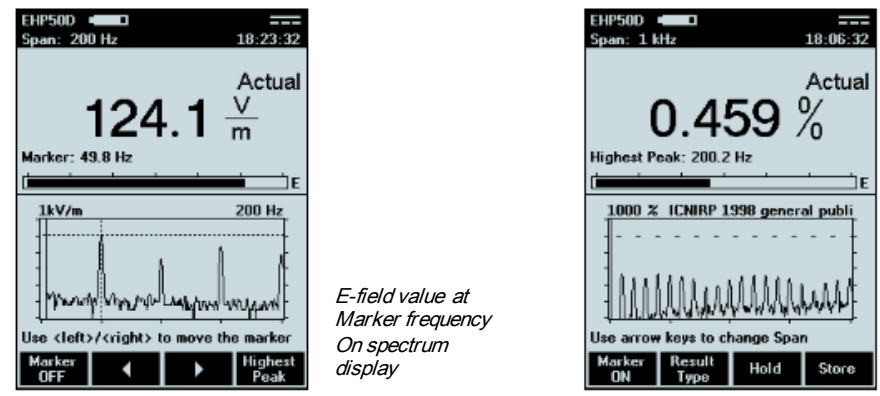

Highest peak as \% of On spectrum

Figure 2. Sample display readings on the NBM550 meter. 


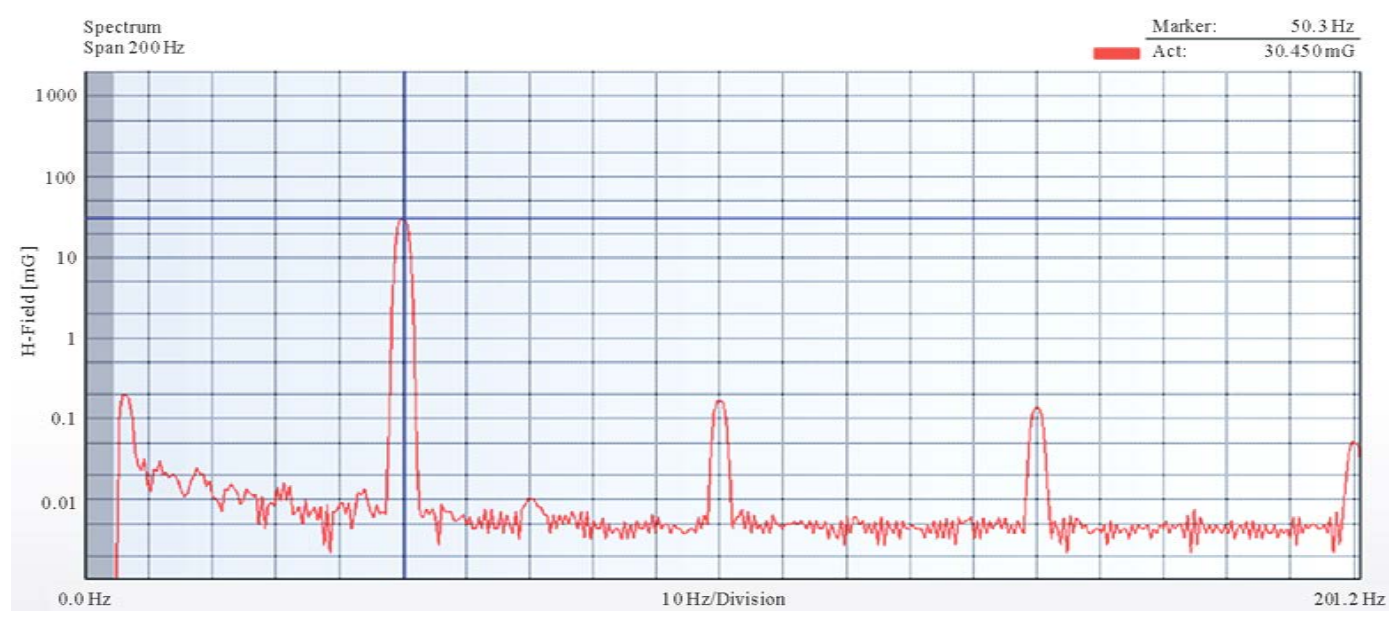

Figure 3. Sample spectrum of field levels at different frequencies, including the first three harmonics, for the Rabiya cables.

an A to D converter followed by a powerful DSP (Digital Signal Processor) that performs signal analysis; and the CPU module that controls all the functions; an EEPROM, that stores the calibration data; an optical interface to allow easy connection to external displays via optical fiber link; a high capacity data logger for standalone continuous acquisition; the control panel with the connections and the ON/OFF switch. In order not to influence the field to be measured, communication between the EHP-50D analyzer and the NBM unit is through a rugged optical fiber cable. The meter and probe were calibrated by the manufacturer.

\subsection{Measurement Methodology}

As the specifications indicate, the EHP-50D can be easily operated through the Broadband Field Meter NBM-550. We measured the electromagnetic field levels at the inhabited areas of Kuwait. As described in the previous subsection existing protocols and standards, (IEEE [39], BS-EN [42], ICNIRP [43], ICNIRP [44], ICNIRP [38], the CDC report by Bowman et al. [40] and the ARPANSA procedure set by Karipidis [41]), are similar in meter specifications and measurement methodology and setup. According to these protocols we may conduct spot and/or 24 hour measurements. However, for the locations under investigation, the 24 hour measurement is not possible since it requires leaving the meter at the monitored location. Therefore, only spot measurements were performed. For each location measurements were conducted at various lateral and longitudinal distances according to the ICNIRP and IEEE recommendations.

According to the international standards, the procedure for measuring includes several readings under the cables and several up to 30 meters laterally. For our measurements the initial point of measurement is under the cables and is centrally located between the two lines of cable groups running in parallel. The next reading is taken directly under one group of cables, at a distance of approximately 10 meters from the initial point. At least 4 more reading points were taken at ten meter distances reaching up to approximately 50 meters from the initial point. At some locations we continue recording readings at further distances at 10 meter intervals. Therefore, in regard to the lateral points we conform to the IEEE standard.

Also according to the IEEE [39], WHO [18] and the three ICNIRP [38] [43] [44] standards the magnetic field under power lines is measured at a height of $1 \mathrm{~m}$ above ground level. A field meter with three-axis probes is used to measure the resultant magnetic field. In all locations the land is uniform and the slope is approximately zero. According to the IEEE when reporting measurement results, the quantity being reported (e.g., the maximum magnetic field or the resultant magnetic field) shall be clearly indicated. We are reporting the maximum magnetic field. A linearly polarized magnetic field with orthogonal components and a circularly polarized magnetic field with orthogonal components will have the same resultant magnetic field.

Also according to the IEEE standard the operator may stay close to the probe, while nonpermanent objects containing magnetic materials or nonmagnetic conductors should be at least three times the largest dimension of the object away from the point of measurement in order to measure the unperturbed field value. The distance between the probe and permanent magnetic objects should not be less than $1 \mathrm{~m}$ in order to accurately measure 
the ambient perturbed field. We adhere to this rule however, since one of the goals of this project is to find if the field from the cables extends to the nearby buildings and houses, we continue our measurement up to the barrier or building. Mostly these are non magnetic objects,therefore, the reading accuracy is not compromised.

The measured levels at Table 2 of results were compared to the ICNIRP [38] limit. It is worth noting that for occupational exposure to $50 \mathrm{~Hz}$ fields, the ICNIRP reference level for public exposure is $2 \mathrm{G}$.

We can summarize that for all locations spot measurements are conducted at a height of one meter. At the beginning of each measurement session the system, (i.e. meter and probe) is tested in a no field zone to confirm correct calibration at zero. The visit to a location is repeated at three times of the day to record levels at different load conditions. The three times are morning afternoon and night. This is also repeated at four seasons of the year.

For each area we present a map that shows the location of the starting point under the cables. GPS coordinates of the initial location of the initial set are presented at the discussion of each location. Therefore, for each location we have a graph of values for several sets and at each set we have graphs for the several distances starting from 0 meters. For each distance of a set we have 12 readings of the field levels in units of milli-Gauss.

\subsubsection{Lateral Profile}

According to the IEEE standard, the lateral profile of the electric field strength at points of interest along a span should be measured at selected intervals in a direction normal to the line at $1 \mathrm{~m}$ above the ground level. Measurements of the lateral (half) profiles should begin from the center line in the area of interest and be made to a lateral distance of at least $30 \mathrm{~m}(100 \mathrm{ft})$ beyond the outside conductor. Several measurements should be performed under the conductors. We have only two groups of conductors where each group consists of three cables running on top of each other. Therefore, only one reading is taken directly under the line group and one centrally between the two groups. The rest are perpendicular to the lines. Our main objective is to find the peak under the cable and the value at distances reaching to inhabited locations or until the field level drops below $4 \mathrm{mG}$, whichever occurs first. Local time should be recorded on the data sheet periodically during the measurements to facilitate later review of the data together with the recorded substation line voltage and load data. We record the local time and date of the commencement of measurements for each location.

\subsubsection{Longitudinal Profile}

The longitudinal profile of the field strength was measured where the field is greatest at midspan, parallel with the line. Measurements of the longitudinal profile were made at 100 meter increments from a point at midspan and repeated at approximately 5 locations. Sometimes the 100 meter is increased or decreased to align with open areas such as an empty land or a side street, in order to allow measurements at up to 50 meters or more. At this new longitudinal location the lateral profile is repeated again. Each starting point is given a set number; therefore, we have set 1 for the initial starting point and set 2 at a distance of 100 meters from set 1 starting point. Each set contains readings taken at several lateral distances starting from a central location under the lines, between the two groups of cables, and considered at 0 meters. The sixth lateral distance is at 50 meters, and so on.

\subsubsection{Harmonic Content}

The harmonics are recorded, however an evaluation shows that the highest harmonic is the third and it is very negligible reaching less than $1 \%$ of the value at the fundamental. Additionally, the maximum field level at the $50 \mathrm{~Hz}$ frequency is much lower than the international standard limit. Therefore, the lower field levels at the odd harmonics have an insignificant effect on raising the total field to reach the limit. Additionally, in order to facilitate a clear overview of the levels at the surveyed locations over the twelve different times of the year, we focus our attention on the level at the fundamental frequency. This allows us to have a clear overview of levels at all points in a location in a focused view for all seasons and time frames.

\section{Results}

As outlined in the Kuwait Ministry of Electricity and Water yearbook [45], Kuwait power is originally generated at $11 \mathrm{kV}$ and $21 \mathrm{kV}$; however, before transmission it is stepped up to 132 and $300 \mathrm{kV}$. This high voltage is stepped down at substations along its path in the distribution network. The step down levels are $132 \mathrm{kV}, 33 \mathrm{kV}$, $11 \mathrm{kV}, 415 \mathrm{~V}$ and $240 \mathrm{~V}$. The Kuwaiti primary network carries $300 \mathrm{kV}$ on overhead lines on steel towers, marked in red. These lines connect power generation stations to each other and to consumption substations 
working at $300 \mathrm{kV}$ and $132 \mathrm{kV}$. The secondary network also carries $132 \mathrm{kV}$ and $33 \mathrm{kV}$ on overhead lines on steel towers in gray color. Cable locations that were surveyed are:

1) Rabiya cables $-5^{\text {th }}$ ring road

2) Alsalam cables $-5^{\text {th }}$ ring road

3) Alsalam cable - Highway 40

4) Ardiya cables $-5^{\text {th }}$ ring road

Cables at all these locations are less than 50 meters from houses and buildings. Additionally many houses have placed car parks below these power transmission lines. Table 1 presents maximum levels and minimum levels over the 12 different visits to each location.

\subsection{Rabiya Cables}

The starting point of this location shown in Figure 4 is at Latitude: 29.300, Longitude: 47.929. At this location cables run parrallel to the $5^{\text {th }}$ ring road between the highway and a residance area. The distance from the houses at some parts is less than 50 meters. Also, the area under the cables is accessable where some residants have used it as a parking space. At these parking spaces high field levels exist. Measurements for the four seasons at the three times of the day are presented in Figure 5 and Figure 6. Each set includes readings at a location for increasing distances from the cables. Table 2 presents results in mGauss and in percentage of the ICNIRP 2000

Table 1. peak and minimum levels at all locations.

\begin{tabular}{|c|c|c|c|c|c|c|c|}
\hline \multirow{2}{*}{$\begin{array}{c}\text { Set no } \\
\text { (longitudinal distance) }\end{array}$} & \multicolumn{3}{|c|}{ Peak } & \multicolumn{3}{|c|}{ Minimum } & \multirow{2}{*}{$\begin{array}{l}\text { Drop to } 5 \mathrm{mG} \\
\quad \text { or less at }\end{array}$} \\
\hline & Level (mG) & Season & time & level (mG) & Season & time & \\
\hline & \multicolumn{7}{|c|}{ Rabiya } \\
\hline $1(0 \mathrm{~m})$ & 43 & summer & night & 23 & Winter & morning & $50 \mathrm{~m}$ \\
\hline $2(100 \mathrm{~m})$ & 52 & summer & $\begin{array}{c}\text { afternoon \& } \\
\text { night }\end{array}$ & 21 & Winter & morning & $50 \mathrm{~m}$ \\
\hline $3(200 \mathrm{~m})$ & 44 & summer & afternoon & 4 & Winter & morning & $>70 \mathrm{~m}$ \\
\hline $4(300 \mathrm{~m})$ & 50 & summer & afternoon & 14 & Winter & morning & $>50 \mathrm{~m}$ \\
\hline \multirow{2}{*}{$5(400 \mathrm{~m})$} & 58 & summer & afternoon & - & - & - & $90 \mathrm{~m}$ \\
\hline & \multicolumn{7}{|c|}{ AlSalam facing RR5 } \\
\hline $1(0 \mathrm{~m})$ & 66 & winter & night & 27 & summer & afternoon & $50 \mathrm{~m}$ \\
\hline $2(100 \mathrm{~m})$ & 43 & winter & afternoon & 22 & summer & afternoon & $50 \mathrm{~m}$ \\
\hline $3(200 \mathrm{~m})$ & 52 & summer & night & 12.29 & fall & afternoon & $50 \mathrm{~m}$ \\
\hline $4(300 \mathrm{~m})$ & 42 & winter & night & 26.23 & summer & afternoon & $50 \mathrm{~m}$ \\
\hline \multirow{2}{*}{$5(400 \mathrm{~m})$} & 35 & winter & night & 13.11 & fall & afternoon & $50 \mathrm{~m}$ \\
\hline & \multicolumn{7}{|c|}{ AlSalam facing HWY40 } \\
\hline $1(0 \mathrm{~m})$ & 69 & summer & afternoon & 18.58 & Winter & morning & $50 \mathrm{~m}$ \\
\hline $2(100 \mathrm{~m})$ & 76.83 & summer & morning & 11.25 & fall & morning & $>70 \mathrm{~m}$ \\
\hline $3(200 \mathrm{~m})$ & 50.5 & summer & morning & 11.24 & fall & morning & $50 \mathrm{~m}$ \\
\hline $4(300 \mathrm{~m})$ & 57 & summer & morning & 9.65 & fall & morning & $>70 \mathrm{~m}$ \\
\hline \multirow[t]{2}{*}{$5(400 \mathrm{~m})$} & 115 & summer & morning & 16.57 & fall & morning & $>50 \mathrm{~m}$ \\
\hline & \multicolumn{7}{|c|}{ Ardiya } \\
\hline $1(0 \mathrm{~m})$ & 57.3 & summer & night & 10.47 & winter & night & $>50 \mathrm{~m}$ \\
\hline $2(100 \mathrm{~m})$ & 54.62 & summer & night & 16 & winter & night & $90 \mathrm{~m}$ \\
\hline $3(200$ m) & 57.62 & summer & night & 18.6 & winter & night & $90 \mathrm{~m}$ \\
\hline $4(300 \mathrm{~m})$ & 58 & summer & night & 19 & winter & $\begin{array}{c}\text { afternoon \& } \\
\text { night }\end{array}$ & $90 \mathrm{~m}$ \\
\hline $5(400 \mathrm{~m})$ & 62.72 & summer & night & 18 & winter & night & $80 \mathrm{~m}$ \\
\hline $6(500 \mathrm{~m})$ & 79.22 & summer & night & 24 & winter & night & $90 \mathrm{~m}$ \\
\hline
\end{tabular}




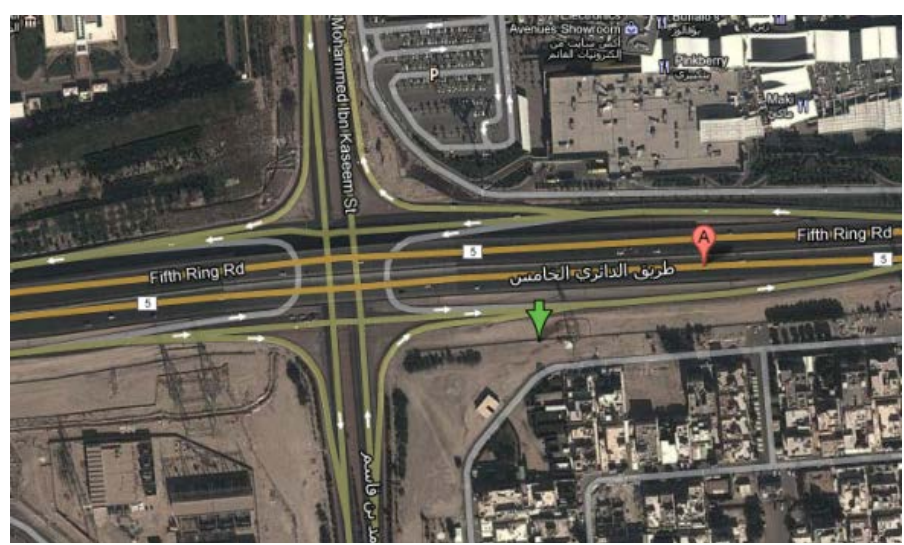

Figure 4. Location of initial point at set 1 location of Rabiya suburb.
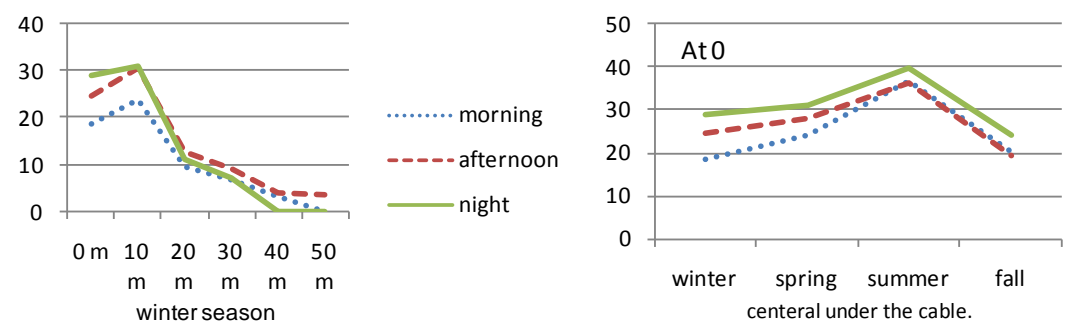

(a)
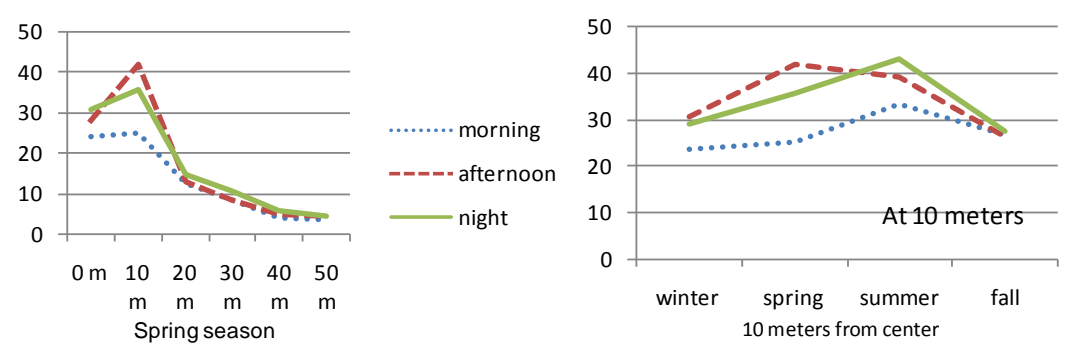

(b)
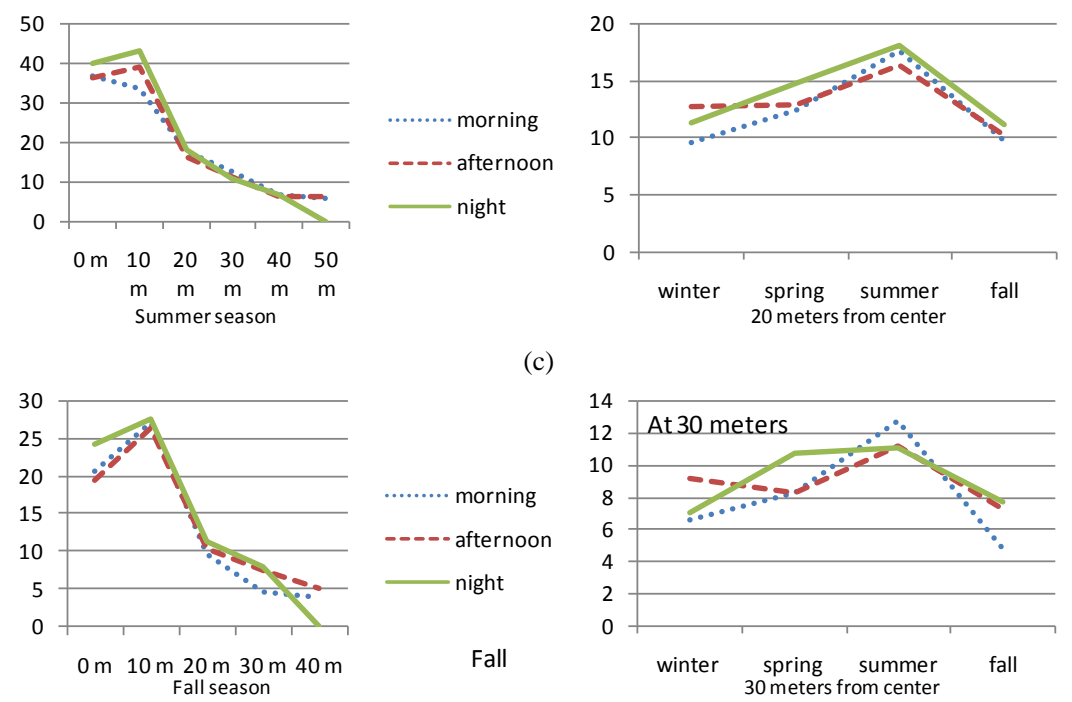

(c)

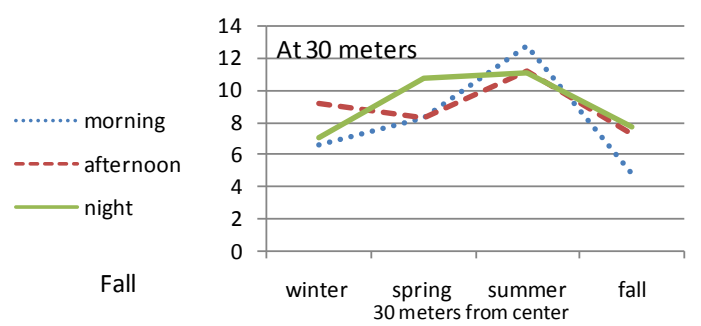

(d)

Figure 5. Rabiya cables set 1 levels in mG (left) at four seasons, and (right) at lateral distances. 

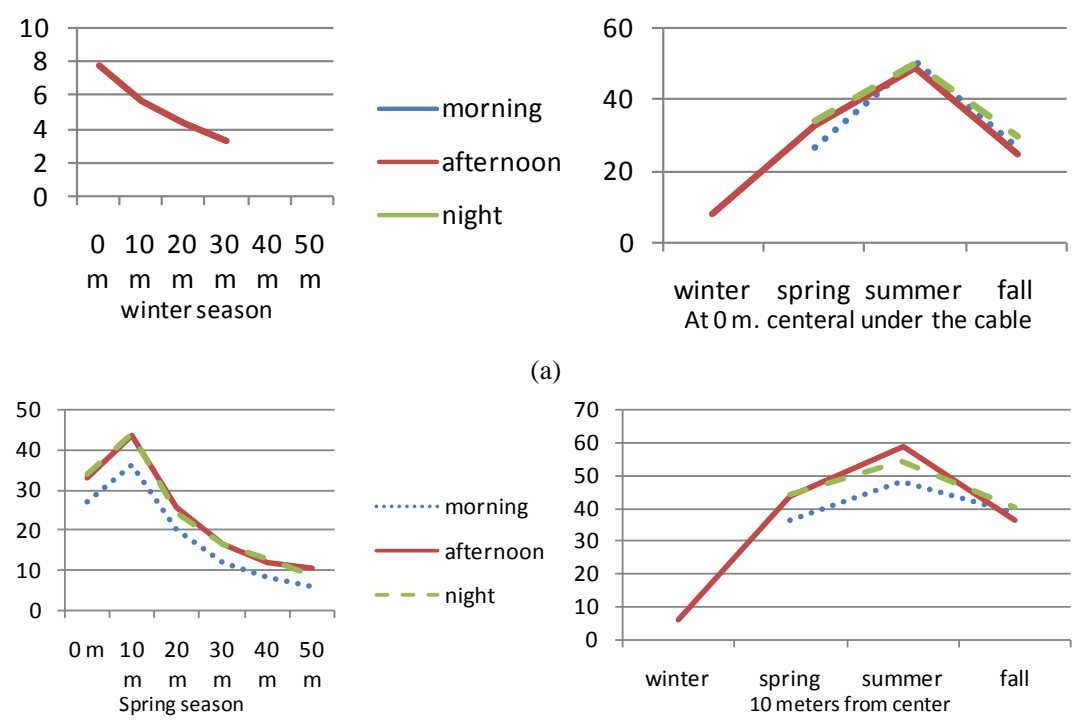

(a)

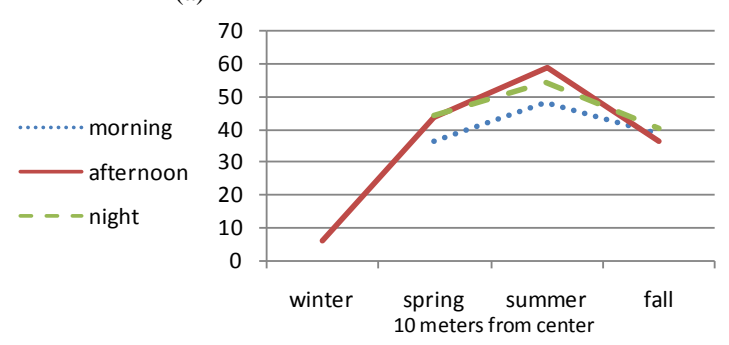

(b)
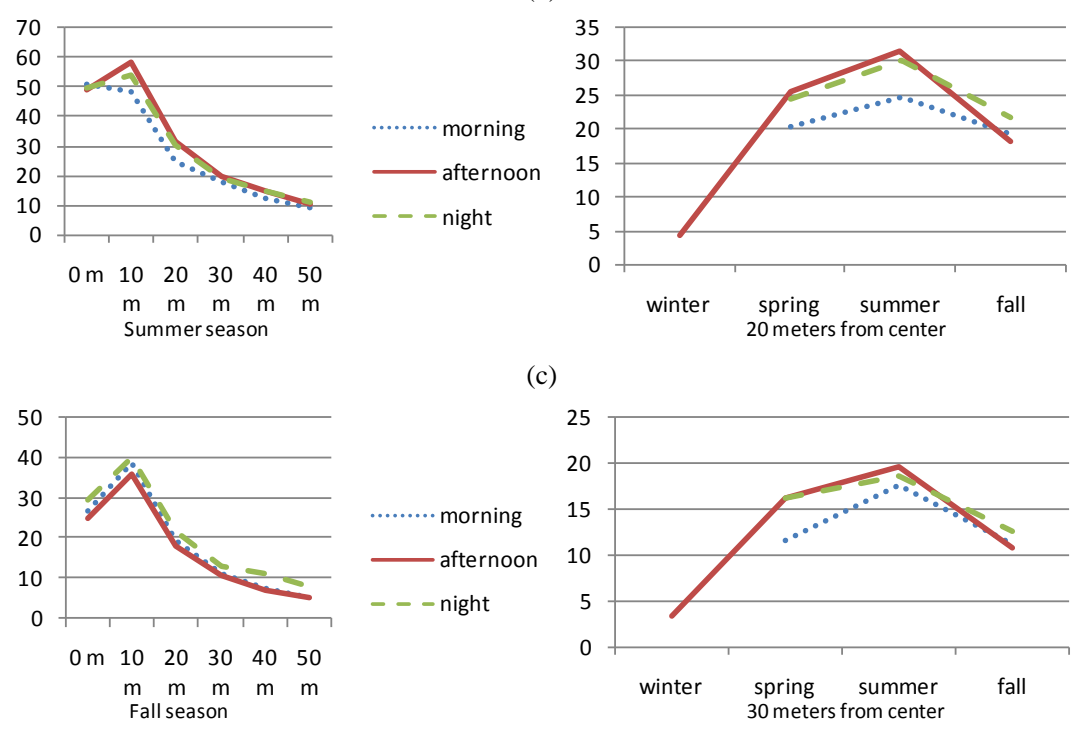

(d)

Figure 6. Rabiya cables set 5 levels in $\mathrm{mG}$ (left) at four seasons and (right) at lateral distances.

limit. Looking at set 1 results centrally under the cable we find the field level ranges between 20 and 40 mG depending on the season and time of day. The maximum is recorded in a summer afternoon while the minimum at a winter morning, extreme levels are shown in Table 1 . The field rises to its peak at a distance of 10 meters from the initial central location reaching $43 \mathrm{mG}$ at a summer night. At this spot, the minimum level is observed in the fall. The level drops to safe levels at a 50 meter distance. At a 100 meter longitudenal distance we obtain set 2 . At 400 meters we obtain set 5 where the field extends to 90 meters before droping to below 5 mG. At all sets the peak level is found at 10 meters from the initial spot under the cables.

\subsection{Alsalam Cables, Facing $5^{\text {th }}$ Ring Road}

The starting point of Alsalam cables is shown in Figure 7 at Latitude: 29.3057 and Longitude: 48.01263. At this location the cables run parallel to the houses at less than 50 meter distances. The distance form the cable to the edge of the street curbe is 20 meters, and from the curb to the house fence is 20 meters. At another house along the same street the distance between the cable and the curb is 28 meters while between the curb and the house 
Table 2. Field levels in Gauss and in percentage of ICNIRP limit at location set 1 under Rabiya cables.

\begin{tabular}{|c|c|c|c|}
\hline Starting Point at $0 \mathrm{~m}$ & Level & Level & Level \\
\hline \multirow{2}{*}{ Winter } & $18.654 \mathrm{mG}$ & $24.538 \mathrm{mG}$ & $31.662 \mathrm{mG}$ \\
\hline & $0.93 \%$ STD & $1.25 \%$ STD & $3.1700 \%$ \\
\hline \multirow{2}{*}{ Spring } & $24.032 \mathrm{mG}$ & $1.40 \%$ STD & $30.522 \mathrm{mG}$ \\
\hline & $1.2 \% \mathrm{STD}$ & $28.114 \mathrm{mG}$ & $3.0500 \%$ STD \\
\hline \multirow{2}{*}{ Summer } & $36.64 \mathrm{mG}$ & $36.37 \mathrm{mG}$ & $3.968 \%$ STD \\
\hline & $1.80 \% \mathrm{STD}$ & $1.80 \%$ STD & $39.69 \mathrm{mG}$ \\
\hline \multirow{2}{*}{ Fall } & $20.51 \mathrm{mG}$ & $0.95 \%$ STD & 2.398\% STD \\
\hline & $1.02 \%$ STD & $19.48 \mathrm{mG}$ & $24.11 \mathrm{mG}$ \\
\hline 10 m away & Level & Level & Level \\
\hline \multirow{2}{*}{ Winter } & $1.18 \%$ STD & 30.486 mG & $2.9666 \%$ \\
\hline & $23.789 \mathrm{mG}$ & $31.50 \%$ & $29.126 \mathrm{mG}$ \\
\hline \multirow{2}{*}{ Spring } & $1.25 \%$ STD & $41.824 \mathrm{mG}$ & $3.5538 \%$ STD \\
\hline & $25.154 \mathrm{mG}$ & $2.1 \%$ STD & $35.553 \mathrm{mG}$ \\
\hline \multirow{2}{*}{ Summer } & $1.70 \%$ STD & $1.95 \%$ STD & $43.05 \mathrm{mG}$ \\
\hline & $33.44 \mathrm{mG}$ & $39.22 \mathrm{mG}$ & $4.282 \%$ STD \\
\hline \multirow{2}{*}{ Fall } & $1.35 \%$ STD & $26.36 \mathrm{mG}$ & $27.46 \mathrm{mG}$ \\
\hline & $26.98 \mathrm{mG}$ & $1.32 \%$ STD & $2.748 \%$ STD \\
\hline 20 m away & Level & Level & Level \\
\hline \multirow{2}{*}{ Winter } & $9.570 \mathrm{mG}$ & $0.63 \%$ & $11.220 \mathrm{mG}$ \\
\hline & $0.49 \%$ STD & $12.685 \mathrm{mG}$ & $1.1144 \%$ \\
\hline \multirow{2}{*}{ Spring } & $12.368 \mathrm{mG}$ & $0.64 \%$ STD & $14.818 \mathrm{mG}$ \\
\hline & $0.60 \%$ STD & $12.966 \mathrm{mG}$ & $1.4792 \%$ STD \\
\hline \multirow{2}{*}{ Summer } & $17.66 \mathrm{mG}$ & $16.35 \mathrm{mG}$ & $1.797 \%$ STD \\
\hline & $0.83 \%$ STD & $0.80 \%$ STD & $18.05 \mathrm{mG}$ \\
\hline \multirow{2}{*}{ Fall } & $9.662 \mathrm{mG}$ & $0.50 \%$ STD & $1.114 \%$ STD \\
\hline & $0.48 \%$ STD & $10.26 \mathrm{mG}$ & $11.12 \mathrm{mG}$ \\
\hline 30 m away & Level & Level & Level \\
\hline \multirow{2}{*}{ Winter } & $0.33 \%$ STD & $9.132 \mathrm{mG}$ & $0.6957 \%$ \\
\hline & $6.553 \mathrm{mG}$ & $0.45 \%$ & $7.088 \mathrm{mG}$ \\
\hline \multirow{2}{*}{ Spring } & $0.42 \%$ STD & $8.324 \mathrm{mG}$ & $1.0776 \%$ STD \\
\hline & $8.327 \mathrm{mG}$ & $0.42 \%$ STD & $10.797 \mathrm{mG}$ \\
\hline \multirow{2}{*}{ Summer } & $0.64 \%$ STD & $0.55 \%$ STD & $11.08 \mathrm{mG}$ \\
\hline & $12.77 \mathrm{mG}$ & $11.16 \mathrm{mG}$ & $1.104 \%$ STD \\
\hline \multirow{2}{*}{ Fall } & $0.24 \%$ STD & $7.311 \mathrm{mG}$ & $7.780 \mathrm{mG}$ \\
\hline & $4.794 \mathrm{mG}$ & $0.35 \%$ STD & $0.775 \%$ STD \\
\hline 40 m away & Level & Level & Level \\
\hline \multirow{2}{*}{ Winter } & $3.254 \mathrm{mG}$ & $0.22 \%$ & - \\
\hline & $0.16 \%$ STD & $4.335 \mathrm{mG}$ & - \\
\hline \multirow{2}{*}{ Spring } & $4.195 \mathrm{mG}$ & $0.24 \%$ STD & $6.026 \mathrm{mG}$ \\
\hline & $0.21 \%$ STD & $4.891 \mathrm{mG}$ & $0.6033 \%$ STD \\
\hline \multirow{2}{*}{ Summer } & $6.677 \mathrm{mG}$ & $6.371 \mathrm{mG}$ & $0.679 \%$ STD \\
\hline & $0.34 \%$ STD & $0.33 \%$ STD & $6.807 \mathrm{mG}$ \\
\hline \multirow{2}{*}{ Fall } & \multirow{2}{*}{ Not Accessible } & $0.20 \%$ STD & $0.498 \%$ STD \\
\hline & & $3.991 \mathrm{mG}$ & $5.008 \mathrm{mG}$ \\
\hline 50 m away & Level & Level & Level \\
\hline Winter & Not Acressible & $3.808 \mathrm{mG}$ & - \\
\hline & & $0.19 \%$ & - \\
\hline & $0.17 \%$ STD & $4.405 \mathrm{mG}$ & $0.4758 \%$ STD \\
\hline Spring & $3.561 \mathrm{mG}$ & $0.22 \%$ STD & $4.770 \mathrm{mG}$ \\
\hline Summer & $\begin{array}{c}5.912 \mathrm{mG} \\
0.26 \% \mathrm{STD}\end{array}$ & $\begin{array}{c}6.264 \mathrm{mG} \\
0.320 \% \mathrm{STD}\end{array}$ & - \\
\hline Fall & $0.20 \%$ SID & ssible due to $p$ & h \\
\hline
\end{tabular}




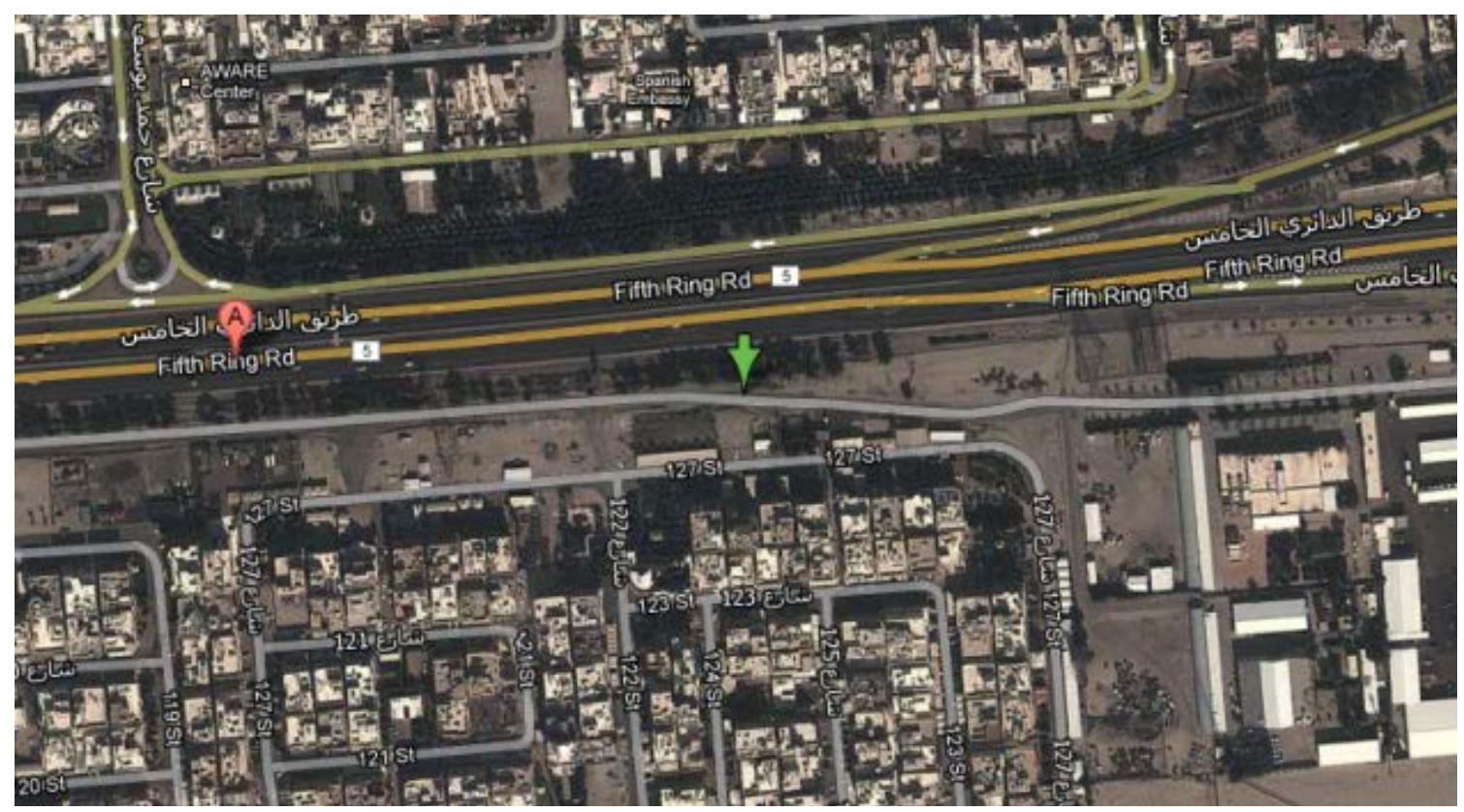

Figure 7. location of initial point at set 1 location of Alsalam $5^{\text {th }}$ RR.

fence is 12 meters. Some residants have used open areas between the curbe and the fence as gardens with seats while areas closer to the cables as parking areas. These parking spaces contain high field levels.

Measurements for the four seasons at the three times of the day are presented in Figure 8 and Figure 9. For set 1 , at 0 meter contrary to the other locations the summer readings were lower than all other seasons, while winter readings were the highest. In general at all seasons, the field levels are higher than $5 \mathrm{mG}$ up to 30 meters. In the winter this extends to 50 meters and the night survey yields an increase at 50 meters. This could be attributed to another source at the house. For set 2, at 0 meter (centrally under the two groups of lines) maximum reading of $44 \mathrm{mG}$ was recorded in the winter night, followed by the summer readings. The peak value at $10 \mathrm{~m}$ is displayed in Table 1.

All seasons yield similar levels reaching the thirties. For set 3, we obtain results similar to the past two sets. Here readings range between the twenties and fourties. Levels drop drastically at 30 meters.

\subsection{Alsalam Cables, Facing HWY 40}

The starting point of Alsalam cables facing highway 40 is shown in Figure 10 at Latitude: 29.30189 and Longitude: 48.02289. Again at this area transmission cables run parallel to the houses at a distance less than 50 meters. We found the houses are closer to the cables than previous areas. The distance from the fence to the cable is 22 meters only. This increases to reach 27.5 meters at the end of the street.

Measurements for the four seasons at the three times of the day are presented in Figure 11 and Figure 12. For set 1 location, at 0 meters, summer yields highest levels followed by fall where it reaches the 40's and 50's. For set 5 location, at 400 meters, we find the highest levels recorded at any seasons or location in Kuwait. Levels in the summer exceeded $100 \mathrm{mG}$ at all times, reaching a peak of $115 \mathrm{mG}$ in a summer morning. Spring was next with levels in the 50's and 60's, while fall yielded levels in the 40's. The high levels in the summer morning can be attributed to increased power consumption due to a sharp rise in the temperature at that specific day. Here, we conducted measurements inside one of the houses at 90 lateral meters, as access was possible due to the house being under construction. Levels in the unoccupied house at a spring afternoon are shown in Table 3.

\subsection{Ardiya Cables}

The starting point of Ardiyacables is shown in Figure 13 at Latitude: 29.29904, Longitude: 47.92365. The cable line at this location runs parallel to the $5^{\text {th }}$ ring road to its north and commercial buildings to its south. The open area under the cables is partially used as customer parking spaces. Again as in the previous locations the parking 


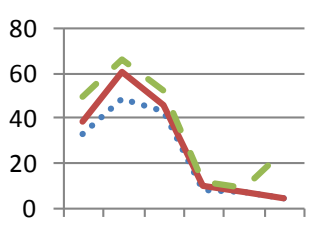

$0 \quad 1020304050$

$\mathrm{m} \mathrm{m} \mathrm{m} \mathrm{m} \mathrm{m}$ winter season
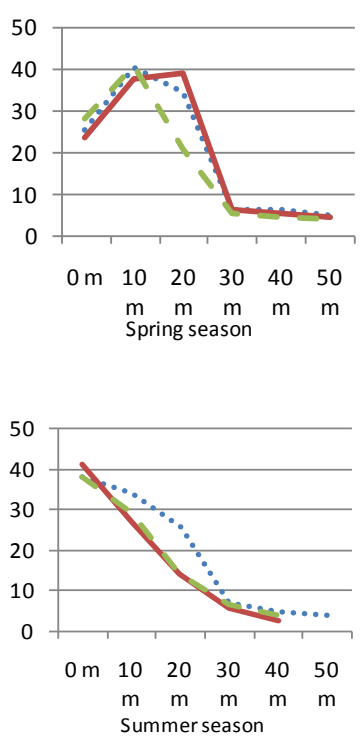

Summer season

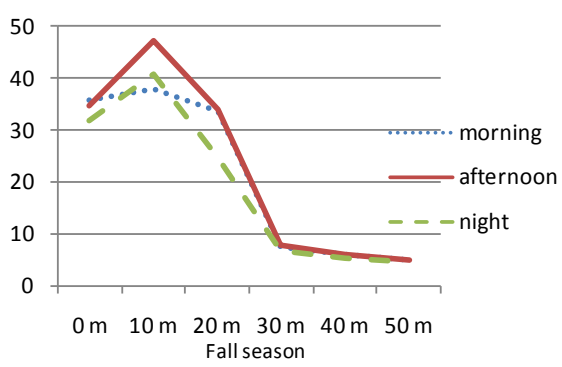

(a)

(b)

(c)
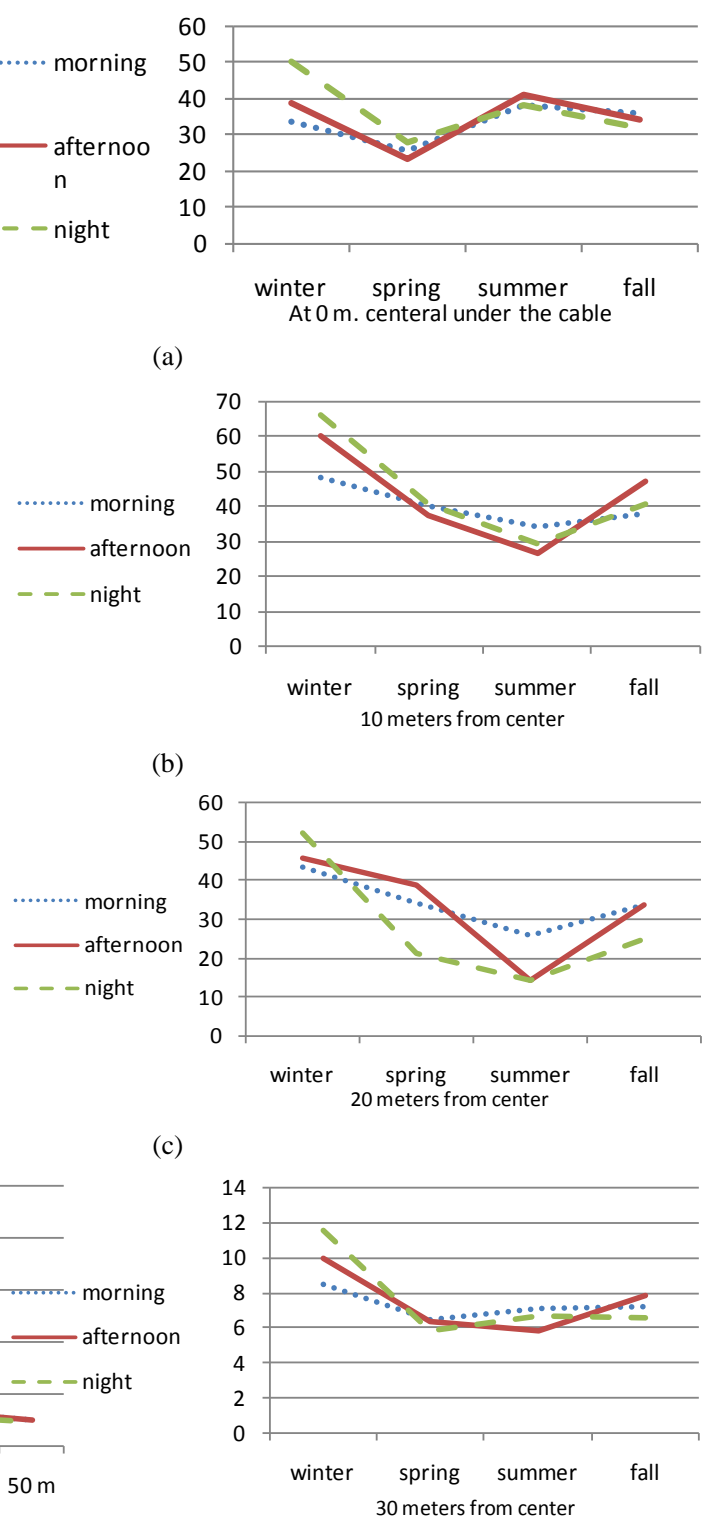

(d)

Figure 8. location of initial point at set 1 location of Alsalam $5^{\text {th }}$ RR.

Table 3. Field levels inside a house in AlSalam HWY40.

\begin{tabular}{ccc}
\hline Level & \multicolumn{1}{c}{ Exact Position } \\
\hline $\begin{array}{c}\text { Inside a House } \\
\text { (Summer - Morning) }\end{array}$ & $5.413 \mathrm{mG}$ & End of hall in basement \\
& $8.512 \mathrm{mG}$ & Basement \\
& $4.169 \mathrm{mG}$ & Corridor - end of hall ground floor \\
\end{tabular}

space is under a high magnetic field. At some spots we found that levels above $4 \mathrm{mG}$ extend to the entrance of these commercial buildings. 


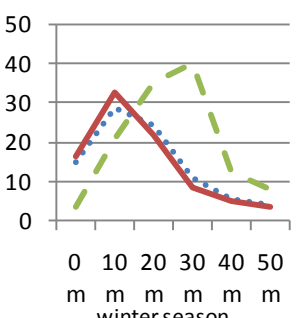
winter season
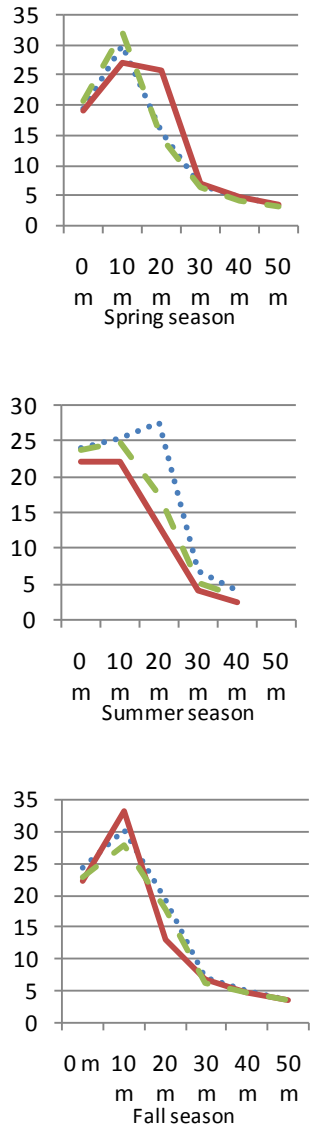

Figure 9. Alsalam $5^{\text {th }} \mathrm{RR}$ cables set 5 levels in $\mathrm{mG}$ (left) at four seasons, and (right) at lateral distances.

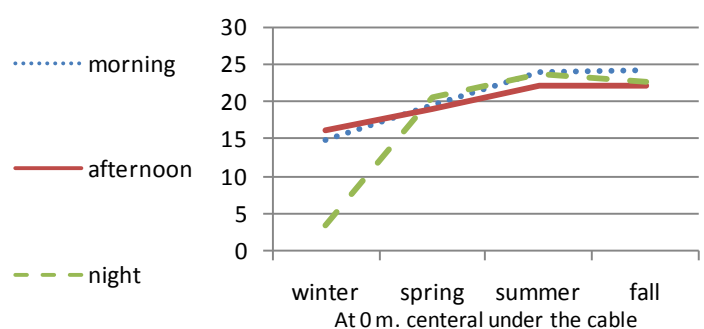

(a)

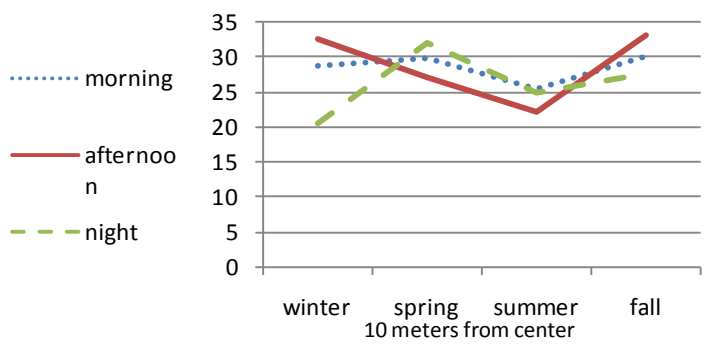

(b)

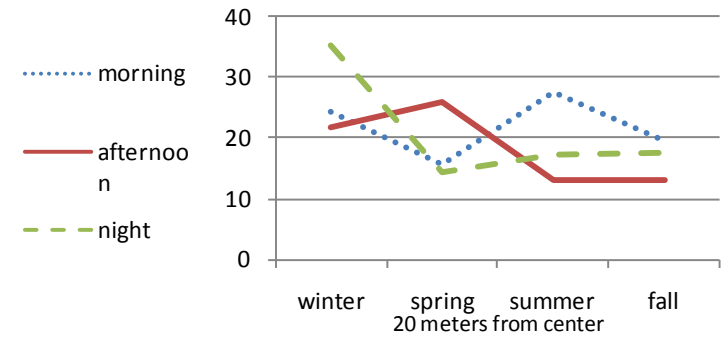

(c)

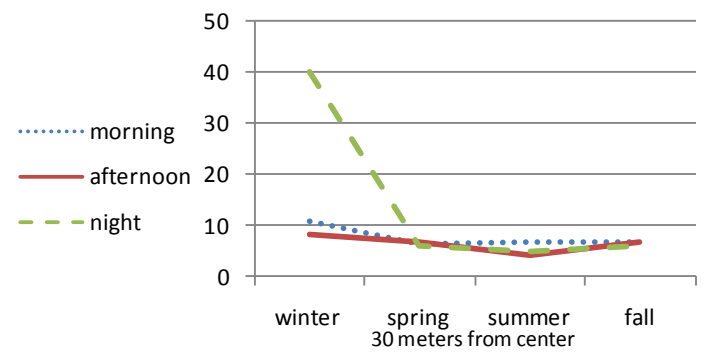

(d)

Measurements for the four seasons at the three times of the day are presented in Figure 14 and Figure 15. Set 1 at 0 meters the maximum levels were recorded in the summer where levels reach mostly above $40 \mathrm{mG}$, while during fall and spring levels reach the 20's. At 50 meters levels drop to around $10 \mathrm{mG}$. Set 2 and 3 yield results similar to set 1, however at set 2 levels above $5 \mathrm{mG}$ extend up to 90 meters in the summer and 60 meters in the spring and fall. Set 4 also yield highest levels in the summer. Fall and spring are around $30 \mathrm{mG}$ while winter yields around $20 \mathrm{mG}$. Here, we reach a publically accessible commercial building and found the level inside the entrance to be $8 \mathrm{mG}$ in the spring. This is less than 1\% of the 1998 ICNIRP standard limit, $(0.5 \%$ of the 2010 ICNIRP limit). However, it is above the $4 \mathrm{mG}$ level set by Ahlbom (2000).

\section{Discussion}

For most sites the highest level is found at 10 meters laterally from the center. This is because at 0 meters the probe is between the two groups of parallel lines, while at 10 meters it is directly under one group of lines which 


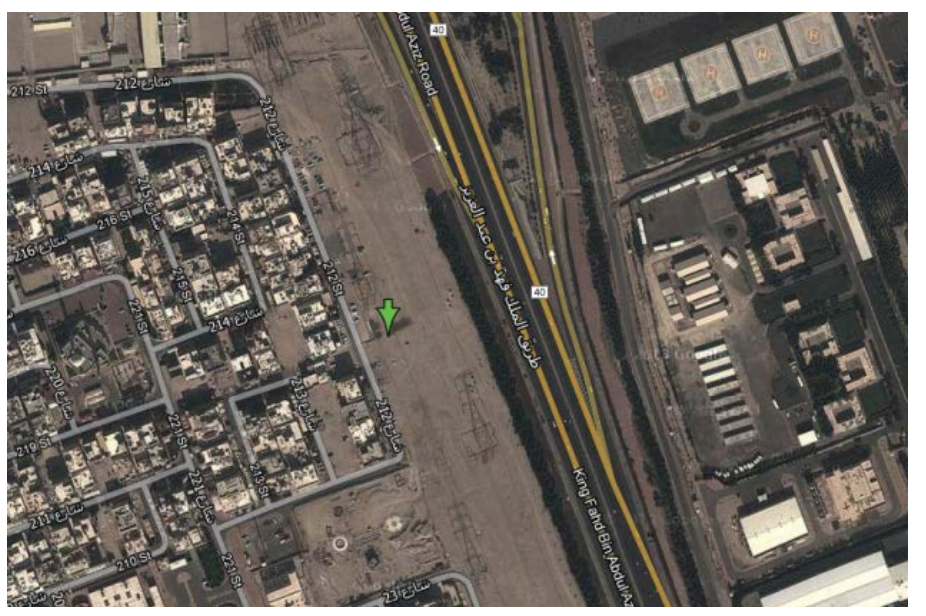

Figure 10. location of initial point at set 2 location of Alsalam HWY40.
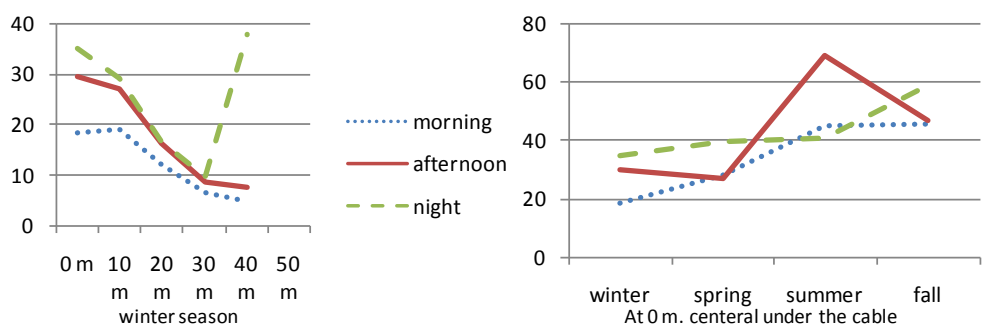

(a)
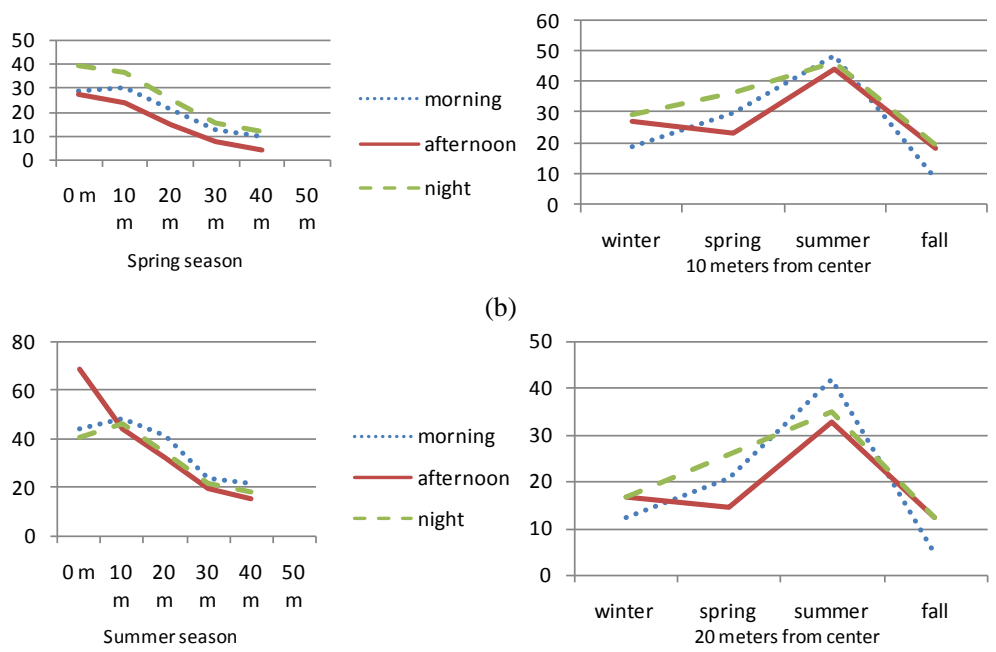

(b)

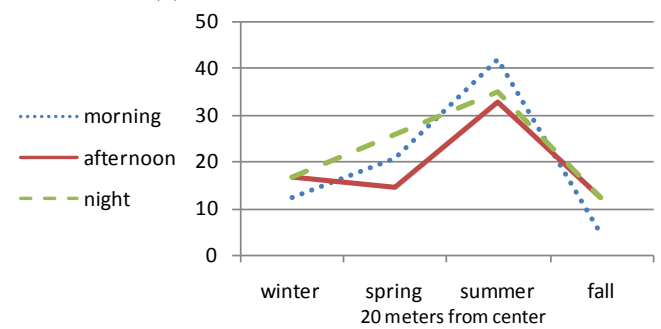

(c)
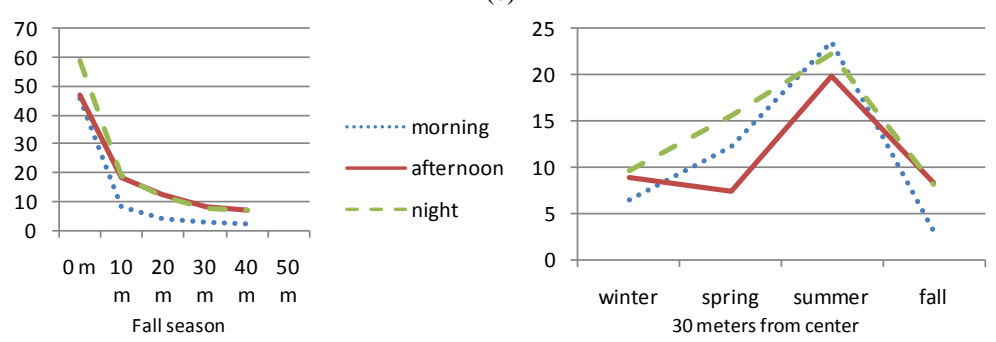

(d)

Figure 11. Alsalam HWY40 cables set 1 levels in mG (left) at four seasons, and (right) at lateral distances. 

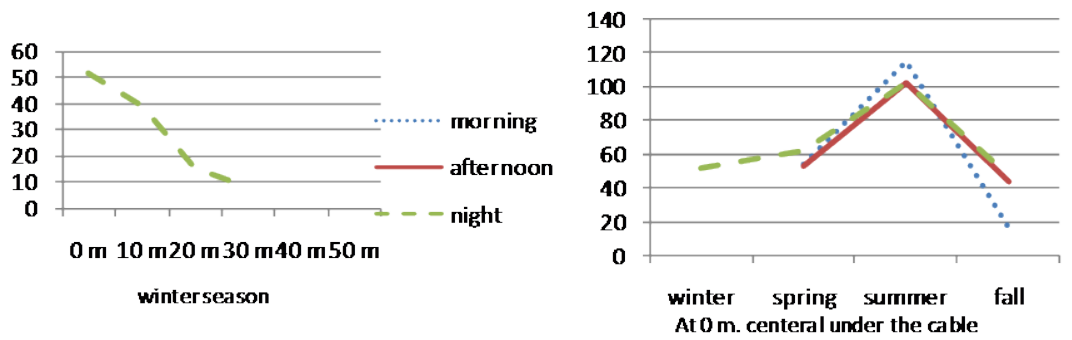

(a)
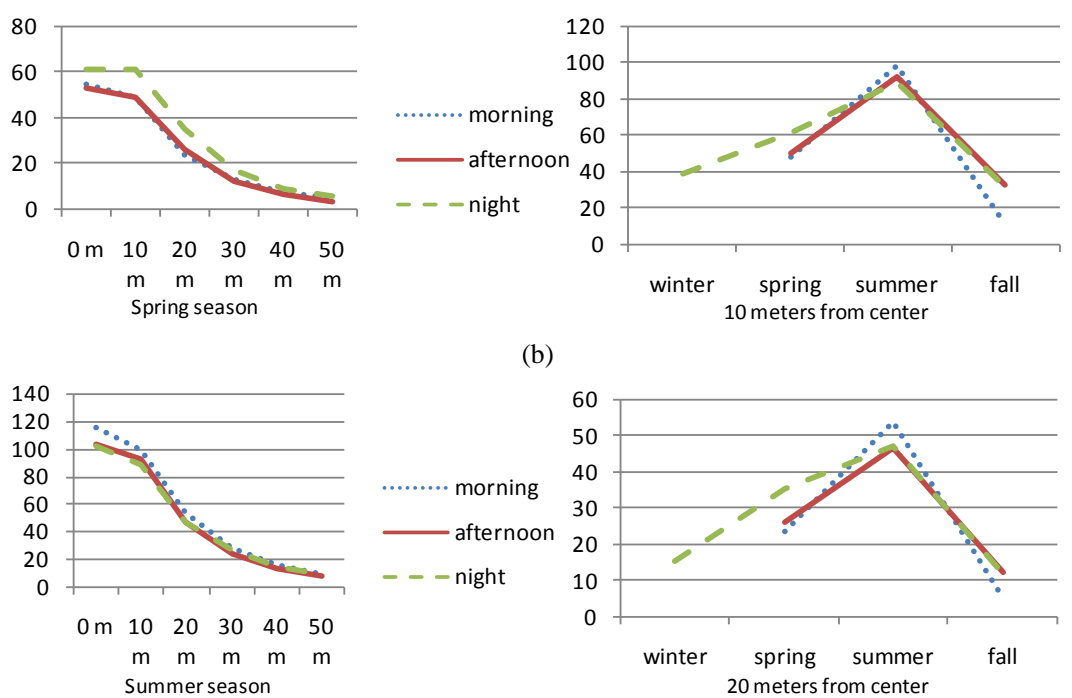

(b)
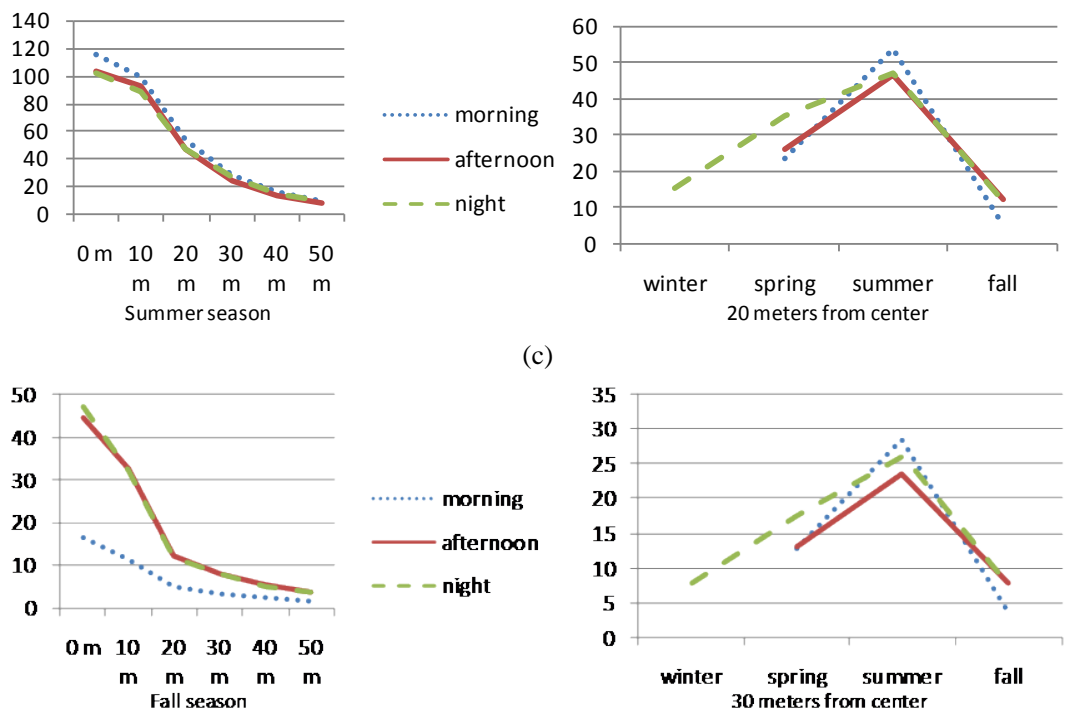

(d)

Figure 12. Alsalam HWY40 cables set 5 levels in mG (left) at four seasons, and (right) at lateral distances.

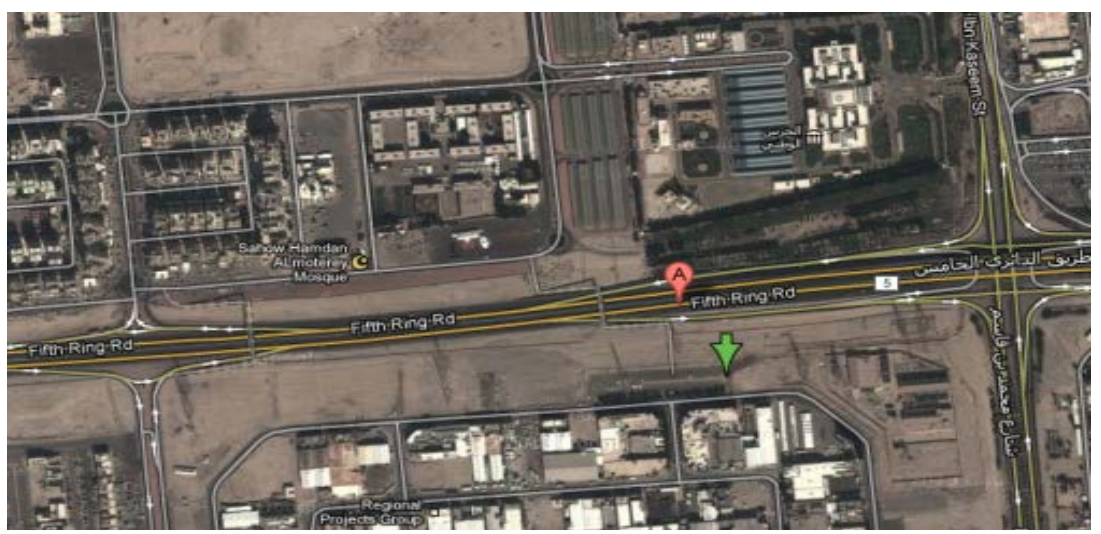

Figure 13. location of initial point at set 1 location of Ardiya on $5^{\text {th }} \mathrm{RR}$. 


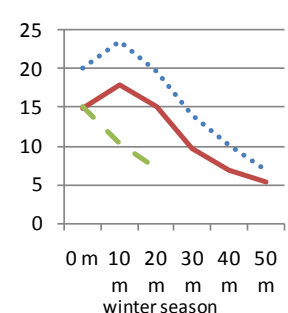

$m m m m$

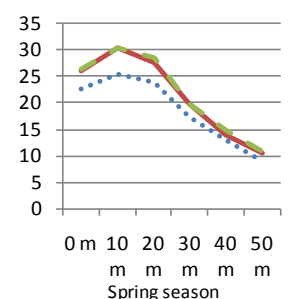

$\mathrm{m} m \mathrm{~m} m$
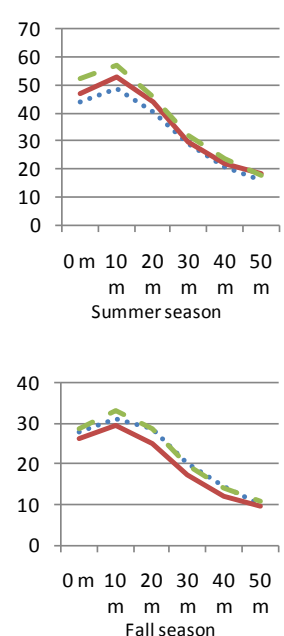

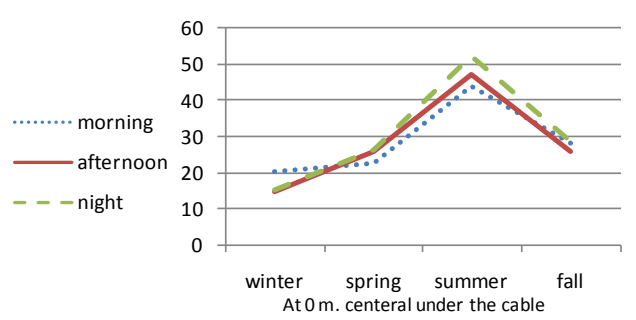

(a)

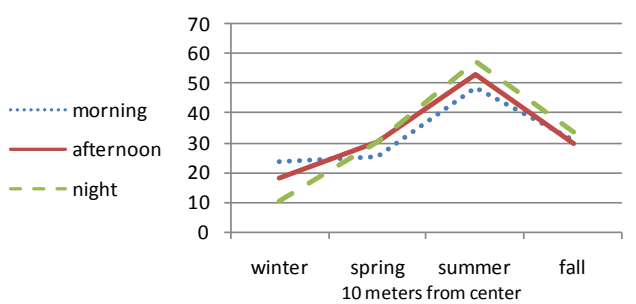

(b)

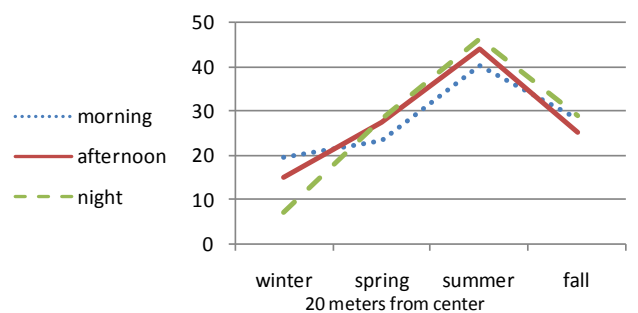

(c)

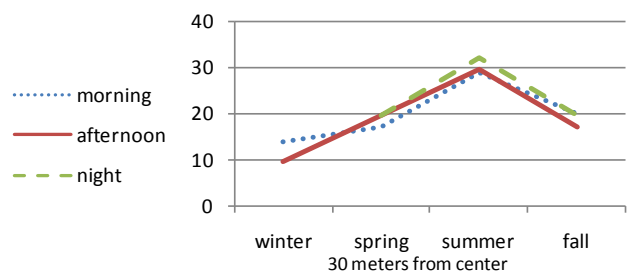

(d)

Figure 14. Ardiya $5^{\text {th }} \mathrm{RR}$ cables set 1 levels in $\mathrm{mG}$ (left) at four seasons, and (right) at lateral distances.
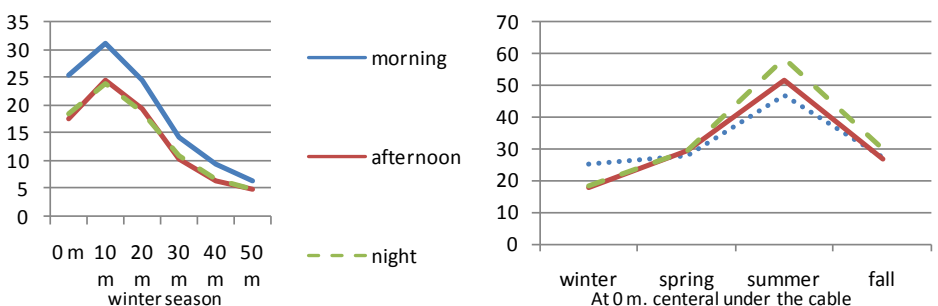

(a)
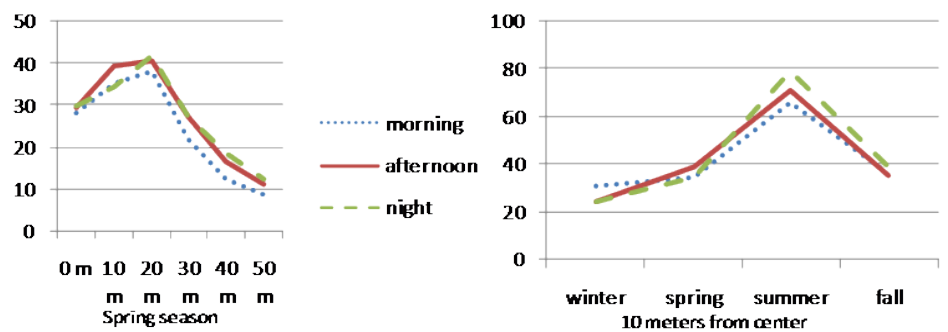

$m m m m m$

(b) 

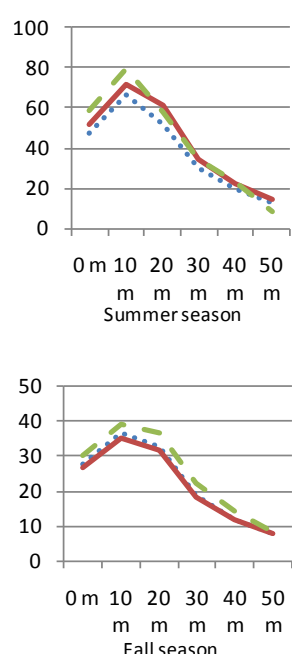

Fall season

Figure 15. Ardiya $5^{\text {th }}$ RR cables set 6 levels in $\mathrm{mG}$ (left) at four seasons, and (right) at lateral distances.

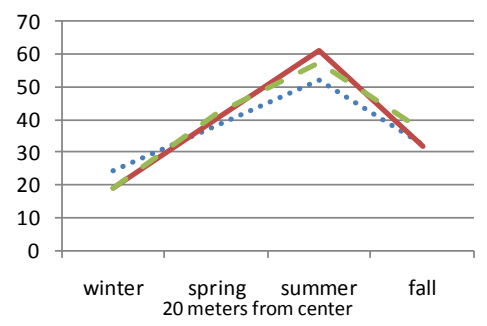

(c)

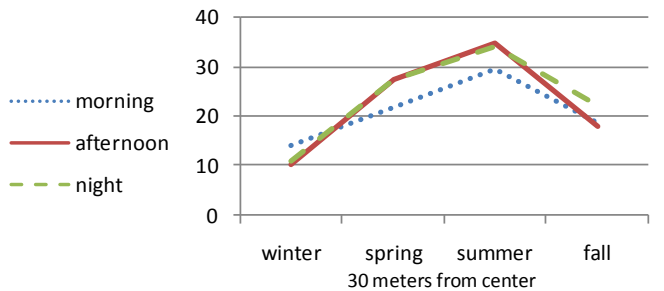

(d)

consists of three cables on top of each other. Highest level is found at Alsalam area facing HWY40 followed by Ardiya. Winter and fall yield lowest levels, while summer yields highest levels. These seasons are toggled in AlSalam area facing $5 \mathrm{RR}$ which can be attributed to a temporary reduction of load on the line at the moment of measurement of a summer afternoon. There, the peak winter level reached $66 \mathrm{mG}$. For all areas the peak levels were always above $50 \mathrm{mG}$. Residents are exposed to these peak levels because the area under the cables are used as parking spaces. The distance between the house fence and the line at most locations was less than 50 meters with a minimum distance of 22 meters in AlSalam facing HWY40. Many longitudinal positions were selected to coincide with an open area such as an unbuilt land or a side street in order to extend the surveyed spots to distances further than 50 meters.

One may argue that the results obtained at all locations were much below the ICNIRP standard limit. However, Ahlbom (2000), Feychting. and Ahlbom (1993), Schuz et al. (2001), consider levels much below our measured values as hazardous. The field level at the entrance of many houses exceeded $4 \mathrm{mG}$ which is considered by many as hazardous. Minimum field levels at $50 \mathrm{~Hz}$ set by various organizations and researchers are presented in Table 4.

\section{Conclusion}

The electromagnetic field from $50 \mathrm{~Hz}$ sources has been under close attention of organizations and scientists due to its possible link to diseases. Many countries and organizations have set limits and have conducted epidemiological studies to find a relation between radiation and diseases. We present the scientific outcome of these studies showing the diseases attributed to LF fields, and the minimum limits set by organizations and scientists.

Our main aim is to monitor the field levels around transmission lines close to inhabited areas in the state of Kuwait and to confirm that houses parallel to the lines are at a safe distance. Measurements were recorded at different seasons for different times of a day. A professional meter and probe was used for the survey. This provided us with an independent knowledge of field levels and locations that require further attention and investigation. These locations are either closer than 50 meters from the transmission lines or are yielding high levels (which are below ICNIRP limit but considered risky by scientists) at houses or facilities used outside the houses. The ICNIRP (1998) has set the limit for the general public at $1000 \mathrm{mG}$ or $1 \mathrm{G}$ and raised it to $2 \mathrm{G}$ in ICNIRP 2010. However, considering the studies that linked leukemia to continuous 4 mG field levels we need to concentrate on locations with levels at $4 \mathrm{mG}$ and above. At these locations we found that measured field levels at parking spaces and close to houses were much higher than $4 \mathrm{mG}$. We found levels higher than $4 \mathrm{mG}$ close to some of the houses at Al Salam, and at the entrance to commercial buildings and at the parking space in Ardiya. Additionally we found that houses were at less than 50 meters from the line. The closest distance was found at AlSalam where the distance between the house fence and the line reaches 22 meters. At these houses, the distance 
Table 4. Minimum field level at $50 \mathrm{~Hz}$ and percentage of risk at certain low field levels.

\begin{tabular}{cc}
\hline Organization or scientist & Recommended safe level at $50 \mathrm{~Hz}$ \\
\hline ICNIRP (2010) & $2 \mathrm{G}$ \\
ICNIRP (1998) & $1 \mathrm{G}$ \\
Ahlbom. et al. (2000) & Two fold risk of leukemia above $4 \mathrm{mG}$ \\
Feychting \& Ahlbom. (1993) & 2.7 Odds Ratio above $2 \mathrm{mG} \&$ 3.8 O.R. above $3 \mathrm{mG}$ \\
Schuz et al. (2001) & 2.4 O.R. at 2mG to $4 \mathrm{mG} \&$ 4.28 O.R. above $4 \mathrm{mG}$ \\
Liburdy et al. (1993) & Increase growth rate for breast cancer cells above $12 \mathrm{mG}$ \\
\hline
\end{tabular}

between the fence and the building was mostly below 3 meters. Therefore, we recommend further investigation of field levels inside these houses to find if levels at bedrooms are above $4 \mathrm{mG}$.

\section{Acknowledgements}

The author sincerely thanks Kuwait foundation for the advancement of Science for generously funding this project under grant number 2010-1508-02.

\section{References}

[1] Shangzun, Y., Pengfei, L. and Ling, N. (2008) Study on Electromagnetic Radiation of Ultra-High Voltage Power Transmission Line. Proceedings of the International Conference on Computer Science and Information Technology, Singapore, 29 August-2 September 2008, 402-406. http://dx.doi.org/10.1109/iccsit.2008.92

[2] Tukimin, R., Mahadi, W.N.L., Ali, M.Y.M. and Thari, M.N.M. (2007) Extremely Low Frequency Electromagnetic Field (ELF EMF) Survey of Residential Areas around Transmission Lines. Proceedings of the Asia-Pacific Conference on Applied Electromagnetics, Melaka, 4-6 December 2007, 1-5. http://dx.doi.org/10.1109/apace.2007.4603908

[3] Karipidis, K.K. and Martin, L.J. (2005) Pilot Study of Residential Power Frequency Magnetic Fields in Melbourne. ARPNSA Technical Report 142.

[4] Mamishev, A.V. and Russell, B.D. (1995) Measurement of Magnetic Fields in the Direct Proximity of Power Line Conductors. IEEE Transactions on Power Delivery, 10, 1211-1216. http://dx.doi.org/10.1109/61.400898

[5] DiPlacido, J., Shih, C.H. and Ware, B.J. (1978) Analysis of Proximity Effects in Electric Field Measurements. IEEE Transactions on Power Apparatus and Systems, PAS-97, 2167-2177. http://dx.doi.org/10.1109/TPAS.1978.354720

[6] Habiballah, I.O., Dawoud, M.M., Al-Balawi, K. and Farag, A.S. (2003) Magnetic Field Measurement \& Simulation of a $230 \mathrm{KV}$ Substation. Proceedings of the International Conference on Non-Ionizing Radiation at UNITEN, Malaysia, 20-22 October 2003, 1-12.

[7] Said, I., Farag, A.S., Hussain, H. and Rahman, N.A. (2004) Measurement of Magnetic Field from Distribution Substations in Malaysia. Proceedings of the Australasian Universities Power Engineering Conference, Brisbane, 26-29 September 2004, 219-222.

[8] Ahlbom, A., Day, N., Feychting, M., Roman, E., Skinner, J., Dockerty, J., Linet, M., McBride, M., Michaella, J., Olsen, J.H., Tynes, T. and Verkasalo, P.K. (2000) A Pooled Analysis of Magnetic Fields and Childhood Leukemia. British Journal of Cancer, 83, 692-708. http://dx.doi.org/10.1054/bjoc.2000.1376

[9] Alkoot, F.M. and Zaeri, N. (2007) Measurement of Low Frequency Electromagnetic Radiation Emitted from Overhead Power Lines in the State of Kuwait. Proceedings of the 7th WSEAS International Conference on Power Systems, Beijing, 15-17 September 2007, 186-191.

[10] Alkoot, F.M. and Zaeri, N. (2011) Experimental Study on Power Frequency Magnetic Radiation from AC Power Lines in the State of Kuwait. Kuwait Journal of Science and Engineering, 38, 79-104.

[11] Qabazard, A.M. (2007) Survey of Electromagnetic Field Radiation Associated with Power Transmission Lines in the State of Kuwait. Proceedings of the International Conference on Electromagnetics in Advanced Applications, Torino, 17-21 September 2007, 795-797. http://dx.doi.org/10.1109/ICEAA.2007.4387423

[12] Wertheimer, N. and Leeper, E. (1979) Electrical Wiring Configurations and Childhood Cancer. American Journal of Epidemiology, 109, 273-284.

[13] Green, L.M., Miller, A.B., Agnew, D.A., Greenberg, M.L., Li, J.H., Villeneuve, P.J. and Tibshirani, R. (1999) Child- 
hood Leukemia and Personal Monitoring of Residential Exposures to Electric and Magnetic Fields in Ontario, Canada. Cancer Causes and Control, 10, 233-243. http://dx.doi.org/10.1023/A:1008919408855

[14] Schuz, J., Grigat, J., Brinkmann, K. and Michaelis, J. (2001) Residential Magnetic Fields as a Risk Factor for Childhood Acute Leukemia: Results from a German Population-Based Case-Control Study. International Journal of Cancer, 91, 728-735. http://dx.doi.org/10.1002/1097-0215(200002)9999:9999<::AID-IJC1097>3.0.CO;2-D

[15] Ahlbom, A., Cardis, E., Green, A.C., Linet, M., Savitz, D.A. and Swerdlow, A.J. (2001) ICNIRP SCI Review of the Epidemiology Literature on EMF and Health. Environmental Health Perspectives, 109, 911-933. http://dx.doi.org/10.2307/3454653

[16] Kheifets, L., Ahlbom, A., Crespi, C.M., Draper, G., Hagihara, J., Lowenthal, R.M., Mezei, G., Oksuzyan, S., Schüz, J., Swanson, J., Tittarelli, A., Vinceti, M. and WunschFilho, V. (2010) Pooled Analysis of Recent Studies on Magnetic Fields and Childhood Leukemia. British Journal of Cancer, 103, 1128-1135.

[17] Foliart, D.E., Pollock, B.H., Mezei, G., Iriye, R., Silva, J.M., Ebi, K.L., Kheifets, L., Link, M.P. and Kavet, R. (2006) Magnetic Field Exposure and Long-Term Survival among Children with Leukemia. British Journal of Cancer, 94, 161-164. http://dx.doi.org/10.1038/sj.bjc.6602916

[18] WHO (2007) Extremely Low Frequency Fields, Environmental Health Criteria Monograph No. 238. Geneva.

[19] Carpenter, D. and Sage, C. (2002) BioInitiative Report: A Rationale for a Biologically-Based Public Exposure Standard for Electromagnetic Fields (ELF and RF). http://www.bioinitiative.org

[20] California Department of Health, California EMF Program (2002) Risk Evaluation: An Evaluation of Possible Risks from Electric and Magnetic Fields (EMFs) from Power Lines, Internal Wiring, Electrical Occupations, and Appliances. Final Report June 2002, California EMF Program, Oakland.

[21] Feychting, M. and Ahlbom, A. (1993) Magnetic Fields and Cancer in Children Residing near Swedish High Voltage Power Lines. American Journal of Epidemics, 7, 467-481.

[22] Loomis, D.P., Savitz, D.A. and Ananth, C.V. (1994) Breast Cancer Mortality among Female Electrical Workers in the United States. Journal of National Cancer Institute, 86, 921-925. http://dx.doi.org/10.1093/jnci/86.12.921

[23] Neutra, R.R., DelPizzo, V. and Lee, G. (2002) An Evaluation of the Possible Risks from Electric and Magnetic Fields (EMFs) From Power Lines, Internal Wiring, Electrical Occupation and Appliances, California EMF Program Final Report.

[24] Kheifets, L., Kheifets, L., Ahlbom, A., Crespi, C.M., Feychting, M., Johansen, C., Monroe, J., Murphy, M.F.G., Oksuzyan, S., Preston-Martin, S., Roman, E., Saito, T., Savitz, D., Schüz, J., Simpson, J., Swanson, J., Tynes, T., Verkasalo, P. and Mezei, G. (2010) A Pooled Analysis of Extremely Low-Frequency Magnetic Fields and Childhood Brain Tumors. American Journal of Epidemiology, 172, 752-761. http://dx.doi.org/10.1093/aje/kwq181

[25] Havas, M. (2004) Biological Effects of Low Frequency Electric and Magnetic Fields. In: Clements-Croome, D., Ed., Electromagnetism and Health, Taylor \& Francis Books, Ltd., London, 25 p.

[26] Schuz, J. (2011) Exposure to Electromagnetic Fields and Cancer: The Epidemiological Evidence. Proceedings of the URSI-General Assembly and Scientific Symposium, Istanbul, 13-20 August 2011.

[27] Lee, G.M., Neutra, R.R., Hristova, L., Yost, M. and Hiatt, R.A. (2002) A Nested Case-Control Study of Residential and Personal Magnetic Field Measures and Miscarriages. Epidemiology, 13, 21-31. http://dx.doi.org/10.1097/00001648-200201000-00005

[28] IARC, International Agency for Research on Cancer. http://www.iarc.fr

[29] National Institute of Environmental Health Sciences. http://www.niehs.nih.gov

[30] Dockerty, J.D., Elwood, J.M., Skegg, D.G. and Herbison, G.P. (1998) Electromagnetic Field Exposures and Childhood Cancers in New Zealand. Cancer Causes \& Control, 9, 299-309. http://dx.doi.org/10.1023/A:1008825220759

[31] Linet, M.S., Hatch, E.E., Kleinerman, R.A., Robison, L.L., Kaune, W.T., Friedman, D.R., Severson, R.K., Haines, C.M., Hartsock, C.T., Niwa, S., Wacholder, S. and Tarone, R.E. (1997) Residential Exposure to Magnetic Fields and Acute Lymphoblastic Leukemia in Children. The New England Journal of Medicine, 337, 1-7.

[32] McBride, M.L., Gallagher, R.P., Theriault, G., Armstrong, B.G., Tamaro, S., Spinelli, J.J., Deadman, J.E., Fincham, S., Robson, D. and Choi, W. (1999) Power-Frequency Electric and Magnetic Fields and Risk of Childhood Leukemia in Canada. American Journal of Epidemiology, 149, 831-842. http://dx.doi.org/10.1093/oxfordjournals.aje.a009899

[33] Savitz, D.A., Wachtel, H., Barnes, F.A., John, E.M. and Tvrdik, J.G. (1988) Case Control Study of Childhood Cancer and Exposure to 60-Hz Magnetic Fields. American Journal of Epidemiology, 128, 21-38.

[34] US National Institute of Environmental Health Sciences (1999) Health Effects from Exposure to Power-Line Frequency Electric and Magnetic Fields, Research Triangle Park, NC.

[35] NRPB (2001) ELF Electromagnetic Fields and the Risk of Cancer: Report of an Advisory Group on Non-Ionising Radiation. Documents of the NRPB, Volume 12, No. 1. 
[36] Lowenthal, R.M., Tuck, D.M. and Bray, I.C. (2007) Residential Exposure to Electric Power Transmission Lines and Risk of Lymphoproliferative and Myeloproliferative Disorders: A Case-Control Study. Internal Medicine Journal, 37, 614-619. http://dx.doi.org/10.1111/j.1445-5994.2007.01389.x

[37] Misakian, M. (1993) ELF Electric and Magnetic Field Measurement Methods. Proceedings of the IEEE International Symposium on Electromagnetic Compatibility, Dallas, 9-13 August 1993, 150-155. http://dx.doi.org/10.1109/isemc.1993.473761

[38] ICNIRP (2010) ICNIRP Guidelines for Limiting Exposure to Time Varying Electric and Magnetic Fields (1Hz-100 KHz). Health Physics, 99, 818-836.

[39] IEEE644 (1994) Procedures for Measurement of Power Frequency Electric and Magnetic Fields from AC Power Lines.

[40] Bowman, J.D., Kelsh, M.A. and Kaune, W.T. (1998) Manual for Measuring Occupational Electric and Magnetic Field Exposure. NIOSH-CDC Publication Number 98-154.

[41] Karipidis, K.K. (2002) Measurement of Residential Power Frequency Magnetic Fields. Australian Radiation Protection \& Nuclear Safety Agency, Technical Report 134.

[42] BS EN 62311 (2008) Assessment of Electronic and Electrical Equipment Related to Human Exposure Restrictions for Electromagnetic Fields (0 Hz-300 GHz) (EN 62311:2008 Identical, IEC 62311:2007).

[43] ICNIRP (1998) ICNIRP Guidelines for Limiting Exposure to Time-Varying Electric, Magnetic and Electromagnetic Fields (Up to 300GHz). Health Physics, 74, 494-522.

[44] ICNIRP (2009) ICNIRP Guidelines on Limits of Exposure to Static Magnetic Fields. Health Physics, 96, 504-514. http://dx.doi.org/10.1097/01.HP.0000343164.27920.4a

[45] Kuwait Ministry of Energy-Electricity and Water (2007) Electrical Energy Statistical Yearbook. 